Supporting Information for:

\title{
6-Nitrochrysene-Derived C8-2'-Deoxyadenosine Adduct: Synthesis of Site-Specific Oligodeoxynucleotides and Mutagenicity in Escherichia coli
}

\author{
Brent V. Powell and Ashis K. Basu \\ Department of Chemistry, University of Connecticut, Storrs, CT 06269
}

Material and Methods

Figure S1. 'H NMR spectrum of 8-bromo-2'-deoxyadenosine .....

Figure S2. ${ }^{13} \mathrm{C}$ NMR spectrum of 8-bromo-2'-deoxyadenosine ..S6

Figure S3. MS spectrum of 8-bromo-2'-deoxyadenosine S7

Figure S4. ${ }^{1} \mathrm{H}$ spectrum of (4) . $\mathrm{S} 8$

Figure S5. MS spectrum of (4)

Figure S6. ${ }^{1} \mathrm{H}$ NMR spectrum of (5) S10

Figure S7. ${ }^{13} \mathrm{C}$ NMR spectrum of (5) $\mathrm{S} 11$

Figure S8. MS spectrum of (5)

Figure S9. ${ }^{1} \mathrm{H}$ NMR spectrum of $(\mathbf{6 b})$ S13

Figure S10. ${ }^{13} \mathrm{C}$ NMR spectrum of $(6 \mathbf{b})$ 
Figure S11. MS spectrum of $(\mathbf{6 b})$.

Figure S12. ${ }^{1} \mathrm{H}$ NMR spectrum of (6a)

Figure S13. ${ }^{13} \mathrm{C}$ NMR spectrum of (6a)

Figure S14. MS spectrum of (6a)

Figure S15. ${ }^{1} \mathrm{H}$ NMR spectrum of (3)

Figure S16. ${ }^{13} \mathrm{C}$ NMR spectrum of (3)

Figure S17. ${ }^{1} \mathrm{H}-{ }^{1} \mathrm{H}$ ROESY spectrum of (3)

Figure S18. MS spectrum of (3)

Figure S19. ${ }^{1} \mathrm{H}$ NMR spectrum of (7)

Figure S20. ${ }^{13} \mathrm{C}$ NMR spectrum of (7)

Figure S21. MS spectrum of (7)

Figure S22. MS Spectrum of $N^{6}$-Benzoyl- $8 N$-(6-aminochrysene)-5'-O-dimethoxytrityl-2'-deoxyadenosine

Figure S23. ${ }^{31} \mathrm{P}$ NMR spectrum of phosphoramidite (8)

Figure S24. MS spectrum of phosphoramidite (8)

Figure S25. ESI-MS spectrum of $N-(d A-8-y l)-6-A C$ modified 12-mer oligodeoxynucleotide

Figure S26. ESI-MS spectrum of $N-(d A-8-y l)-6-A C$ modified 15-mer oligodeoxynucleotide 
Figure S27. 20\% PAGE Gel of $N-(d A-8-y l)-6-A C$ modified 12-mer and 15-mer oligodeoxynucleotides........

Scheme S1. Summary of procedure for construction of recombinant DNA vector....

Table S1. Mutational frequency in wild type (-) SOS and (+) SOS E. coli (AB1157) cells 


\section{Materials and Methods}

All reagents were purchased from commercial chemical suppliers and used without further purification unless otherwise noted. All reactions were performed in round bottomed flasks sealed with rubber septa, under an atmosphere of nitrogen, and stirred with a TeflonTM-coated magnetic stir bar unless otherwise noted. Temperatures above $23{ }^{\circ} \mathrm{C}$ were controlled by a temperature modulator. Predried tetrahydrofuran $(\mathrm{THF})$, benzene, toluene, acetonitrile $(\mathrm{MeCN})$, methanol $(\mathrm{MeOH})$, and triethylamine $\left(\mathrm{Et}_{3} \mathrm{~N}\right)$, were degassed with argon for $60 \mathrm{~min}$. Reactions were monitored by thin layer chromatography (TLC) using J.T Baker 2.5 x $7.5 \mathrm{~cm}$ silica gel flexible TLC sheets and visualized using UV $(254 \mathrm{~nm})$. Volatile solvents were removed using a rotary evaporator under reduced pressure. Silica gel chromatography was performed using Sorbent Technologies 60 A, 230 x 400 mesh silica gel (40-63 $\mu \mathrm{m})$.

${ }^{1} \mathrm{H}$ NMR and ${ }^{13} \mathrm{C}$ NMR were obtained in $\mathrm{CDCl}_{3}$ and DMSO- $\mathrm{d}_{6}$ on Bruker Advance $400 \mathrm{MHz}$ spectrometers with ${ }^{13} \mathrm{C}$ operating frequencies of $100 \mathrm{MHz}$ and analyzed using MestReNova. Chemical shifts are reported in parts per million $(\delta)$ relative to residual chloroform (7.26 ppm for ${ }^{1} \mathrm{H}$ and $77.16 \mathrm{ppm}$ for ${ }^{13} \mathrm{C}$ ). Data for ${ }^{1} \mathrm{H}$ NMR spectra are reported as follows: chemical shift (multiplicity, number of hydrogens and assignment). Multiplicity is designated as s (singlet), $\mathrm{d}$ (doublet), $\mathrm{t}$ (triplet), $\mathrm{q}$ (quartet), $\mathrm{p}$ (pentet), or m (multiplet).

\section{HRMS Data:}

Small molecules: LCMS data was obtained using electrospray ionization (ESI) on QStar Elite Electrospray/Nanospray QuadrupoleTime-of-Flight Mass Spectrometer (AB Sciex) in positive ionization mode and the data was analyzed using MassLynx.

Oligonucleotides: Masses were acquired by Thermo Scientific Q Exactive ${ }^{\mathrm{TM}} \mathrm{HF}$ Mass Spectrometer in the negative ionization mode with an electrospray ionization source. 


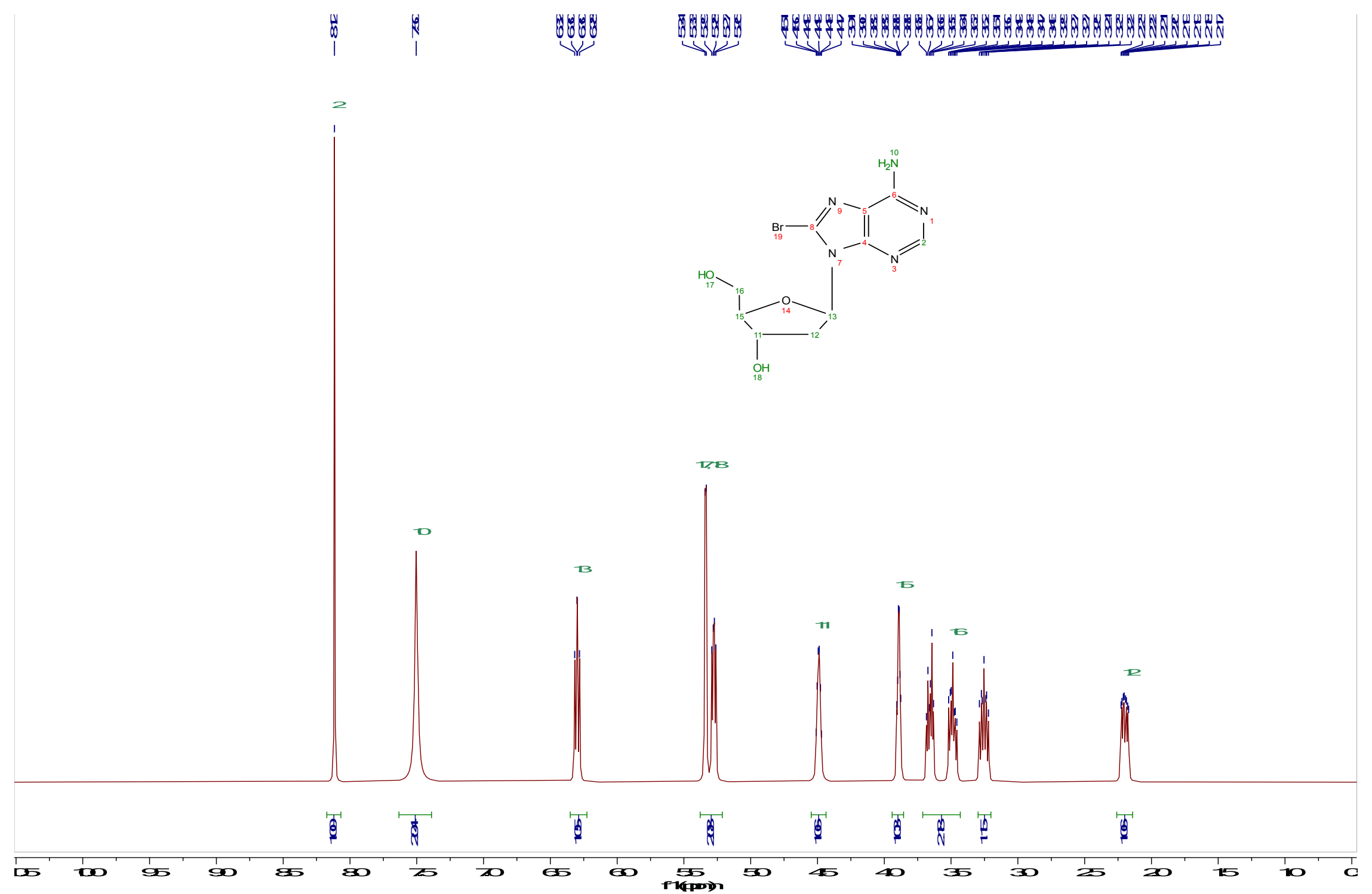

Figure S1. ${ }^{1}$ H NMR spectrum of 8-bromo-2'-deoxyadenosine 


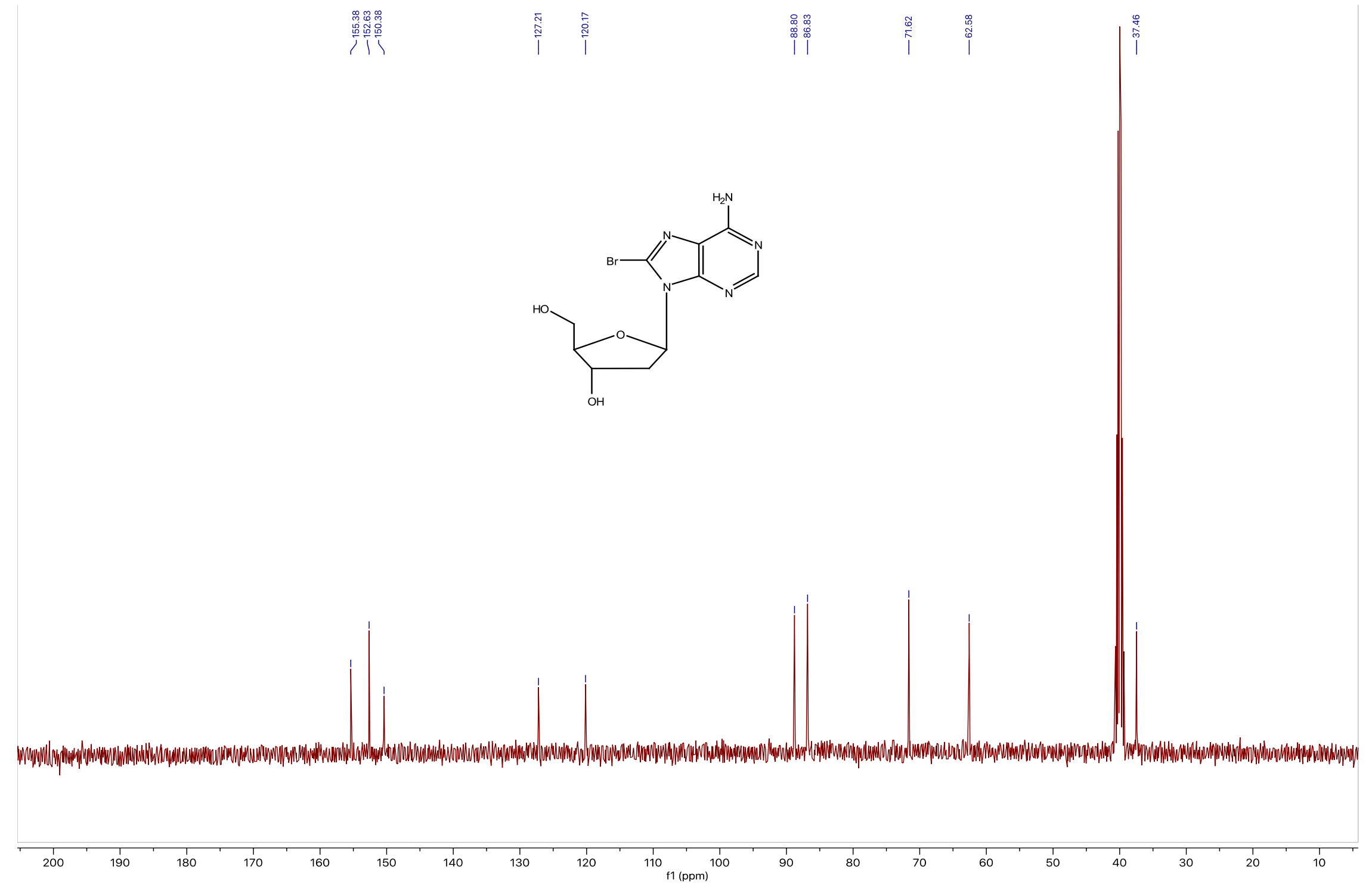

Figure S2. ${ }^{13} \mathrm{C}$ NMR spectrum of 8-bromo-2'-deoxyadenosine 


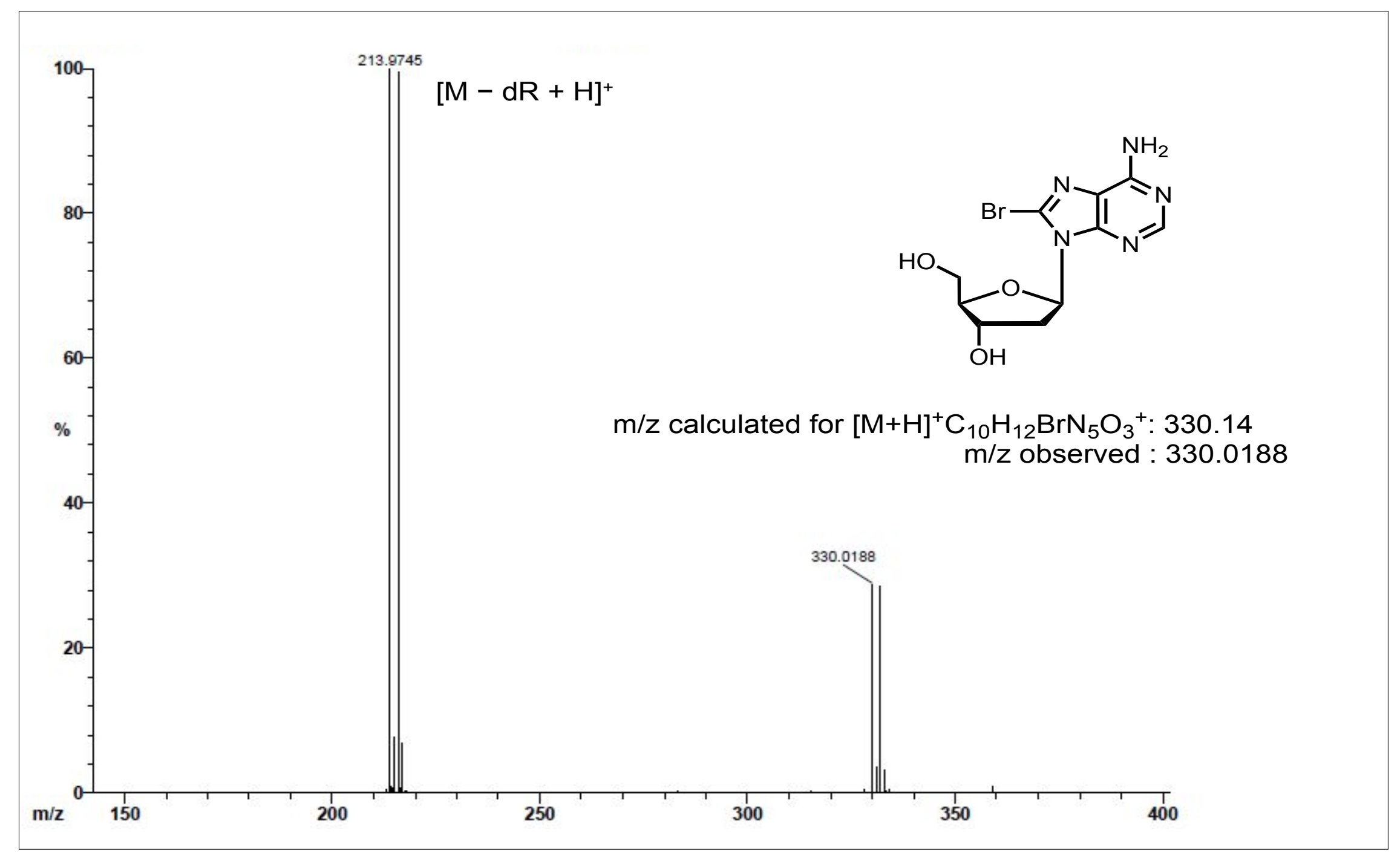

Figure S3. MS spectrum of 8-bromo-2'-deoxyadenosine 


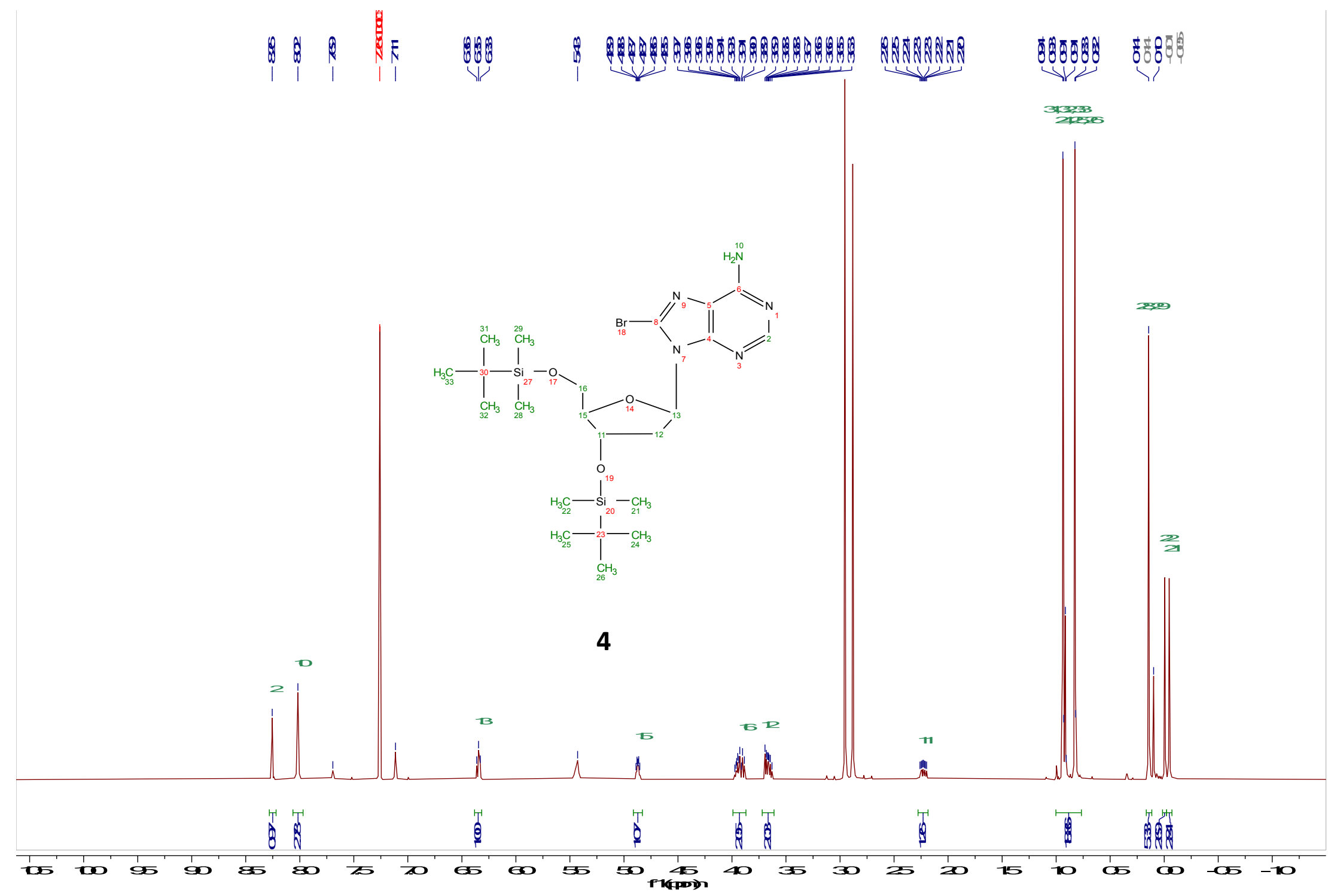

Figure S4. ${ }^{1}$ H NMR spectrum of 8-bromo-3', 5'-O-bis(tert-butyldimethylsilyl)-2'-deoxyadenosine (4) 


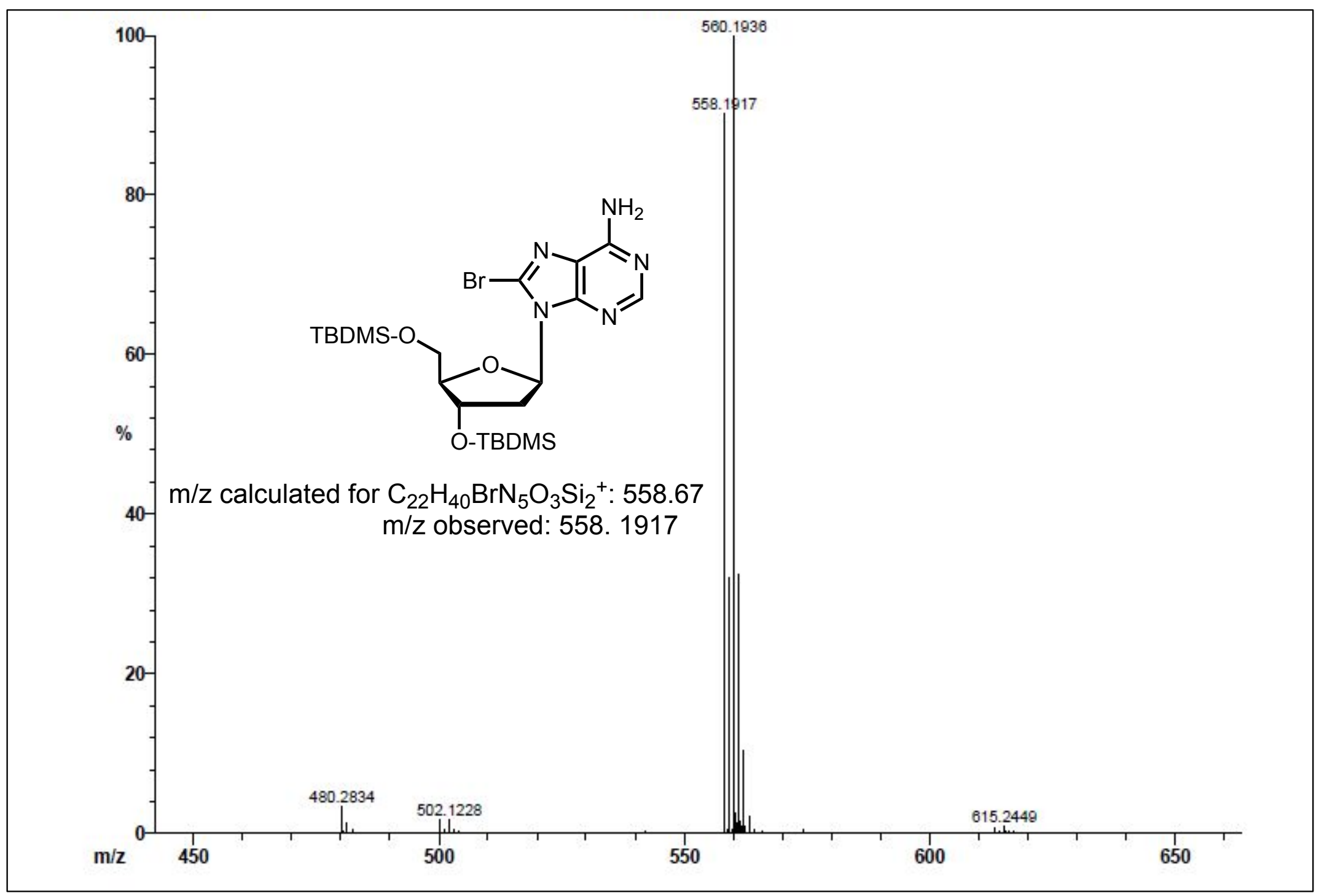

Figure S5. MS spectrum of 8-bromo-3', 5'-O-bis(tert-butyldimethylsilyl)-2'-deoxyadenosine (4) 


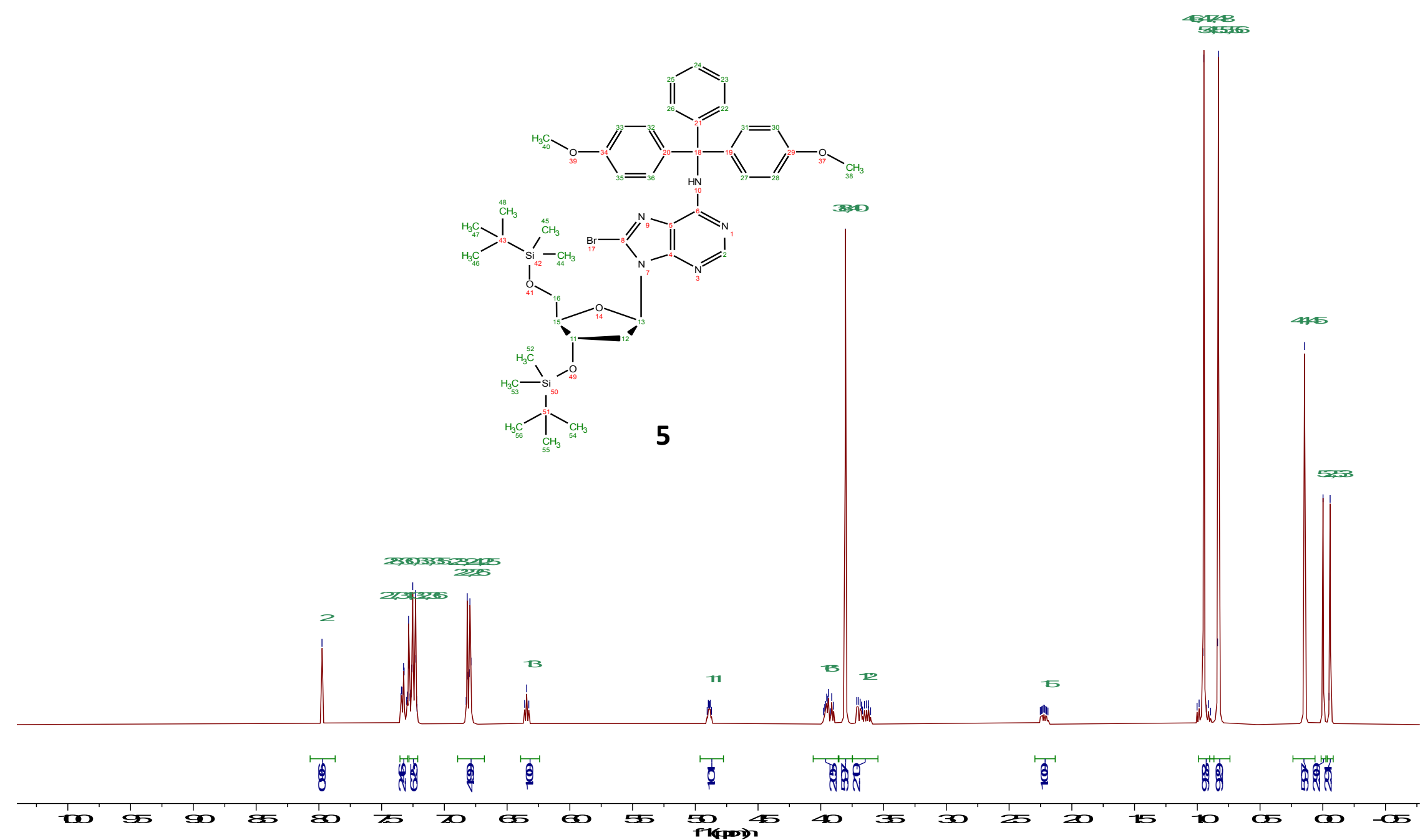

Figure S6. ${ }^{1}$ H NMR spectrum of 8-bromo-3', 5'-O-bis(tert-butyldimethylsilyl)-N6'-dimethoxytrityl-2'-deoxyadenosine (5) 


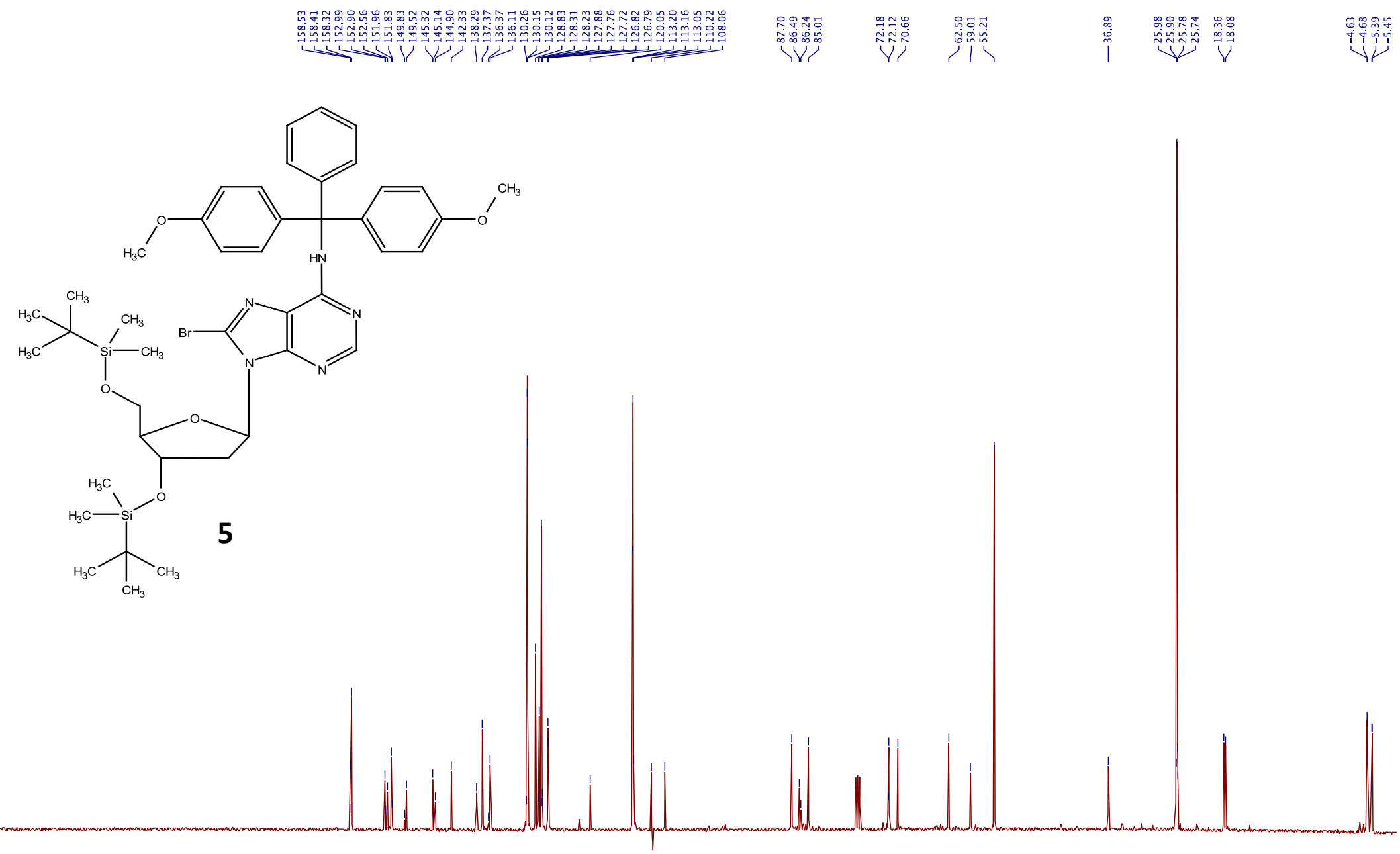

Figure S7. ${ }^{13} \mathrm{C}$ NMR of 8-bromo-3', 5'-O-bis(tert-butyldimethylsilyl)-N ${ }^{6}$-dimethoxytrityl-2'-deoxyadenosine (5) 


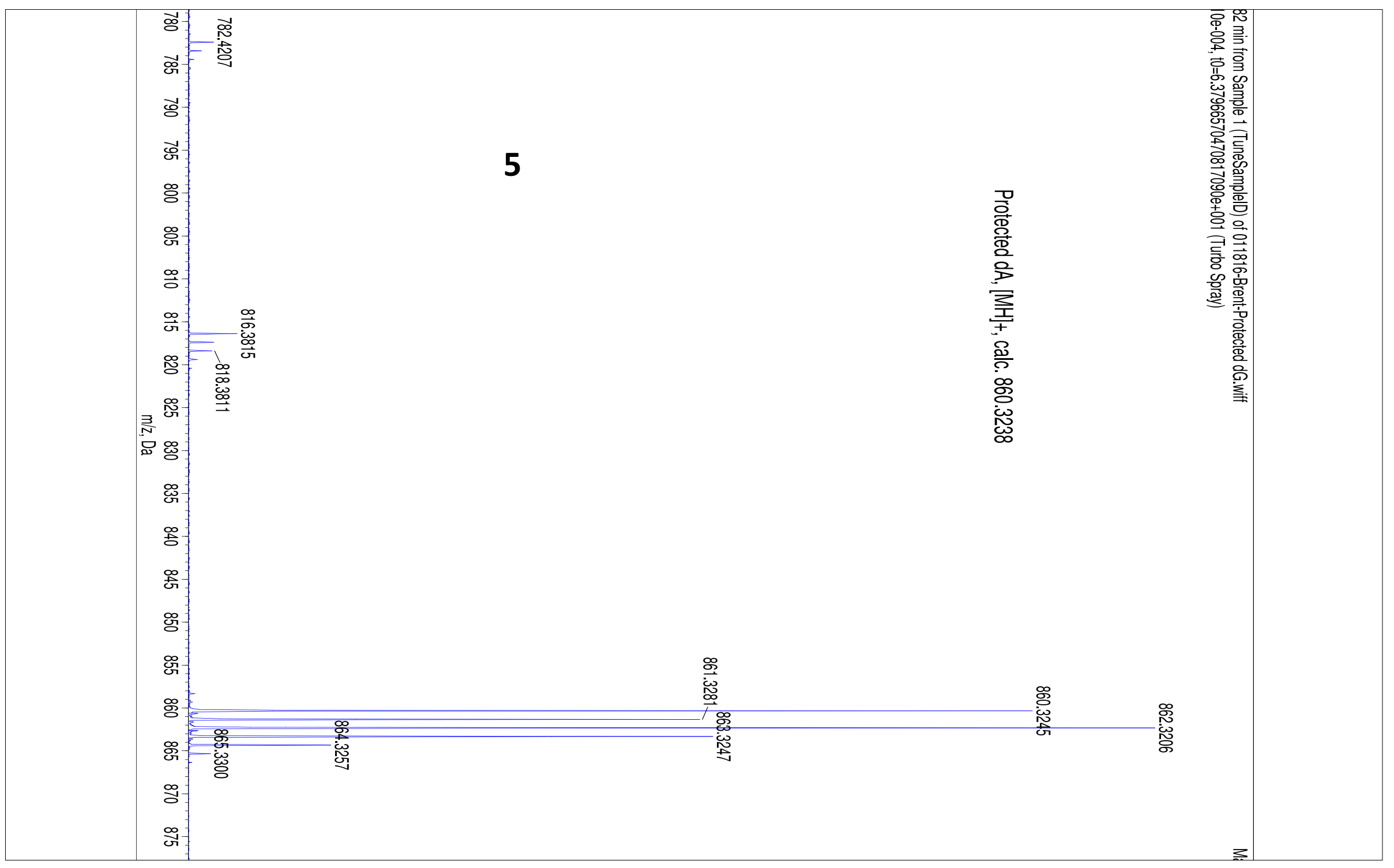

Figure S8. MS spectrum of 8-bromo-3', 5'-O-bis(tert-butyldimethylsilyl)-N ${ }^{6}$-dimethoxytrityl-2'-deoxyadenosine (5) 


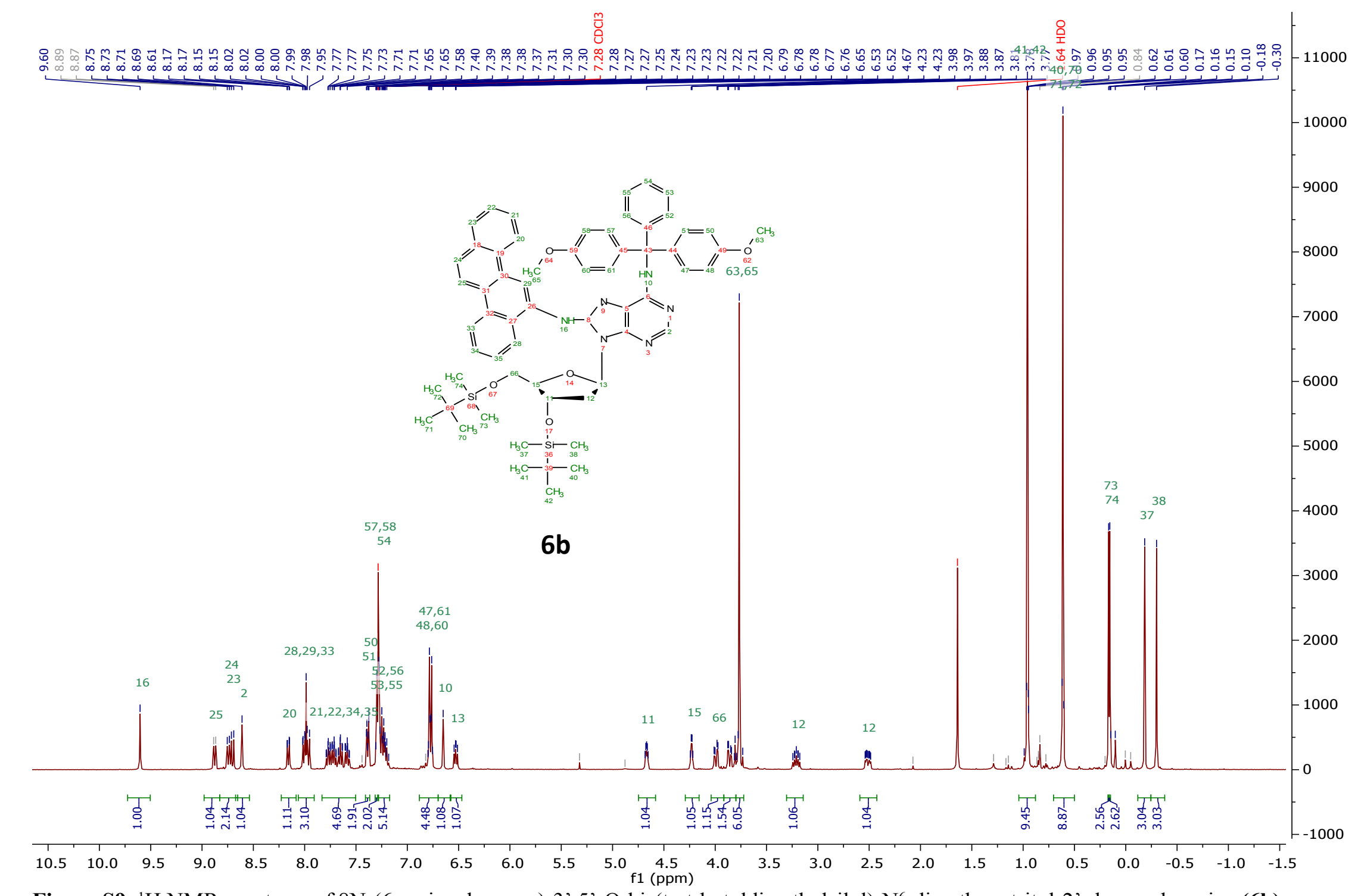

Figure S9. ${ }^{1} \mathrm{H}$ NMR spectrum of $8 \mathrm{~N}$-(6-aminochrysene)-3',5'-O-bis(tert-butyldimethylsilyl)-N ${ }^{6}$-dimethoxytrityl-2'-deoxyadenosine (6b) 

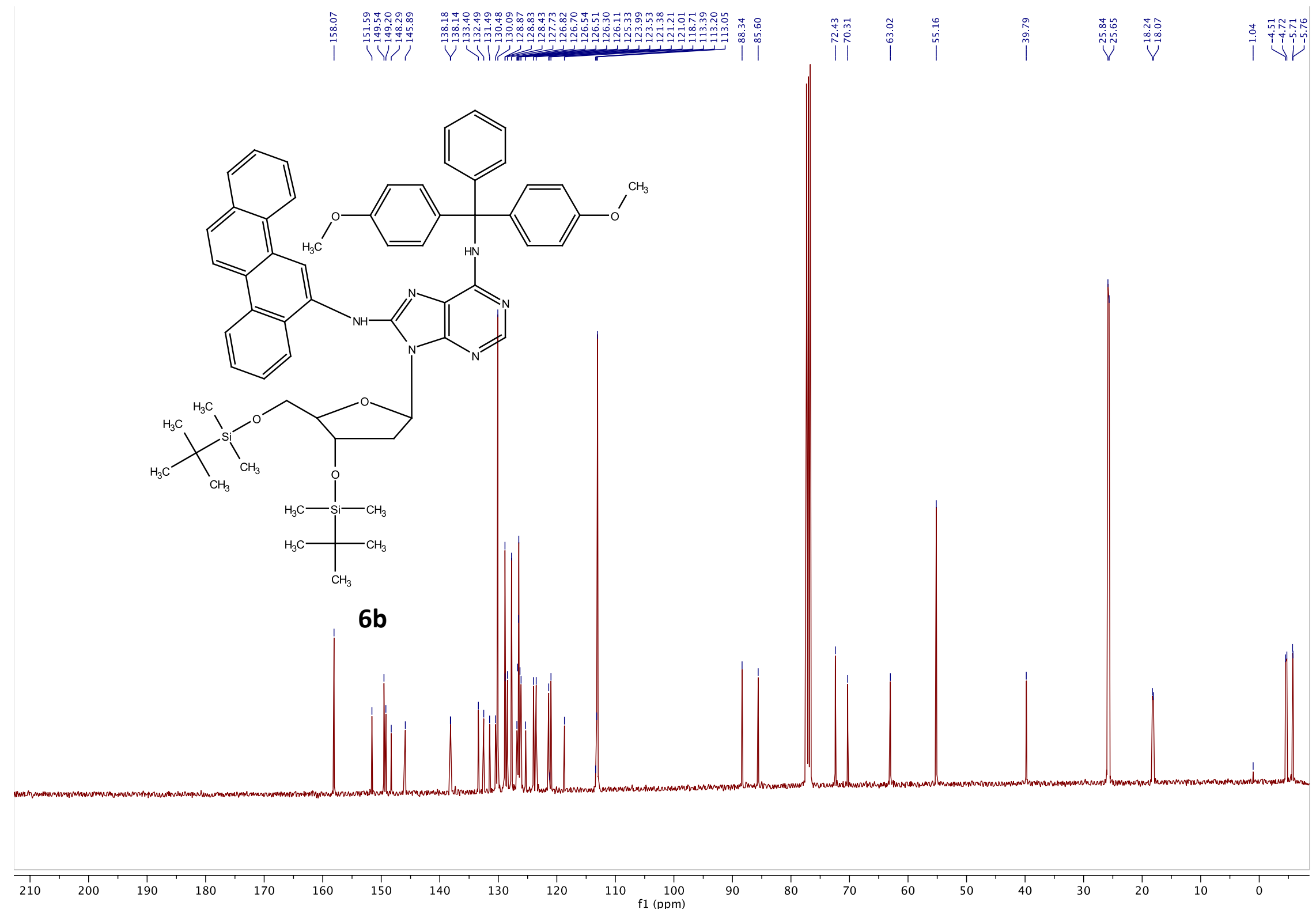

Figure S10. ${ }^{13} \mathrm{C}$ NMR spectrum of 8N-(6-aminochrysene)-3',5'-O-bis(tert-butyldimethylsilyl)-N6'dimethoxytrityl-2'-deoxyadenosine (6b) 


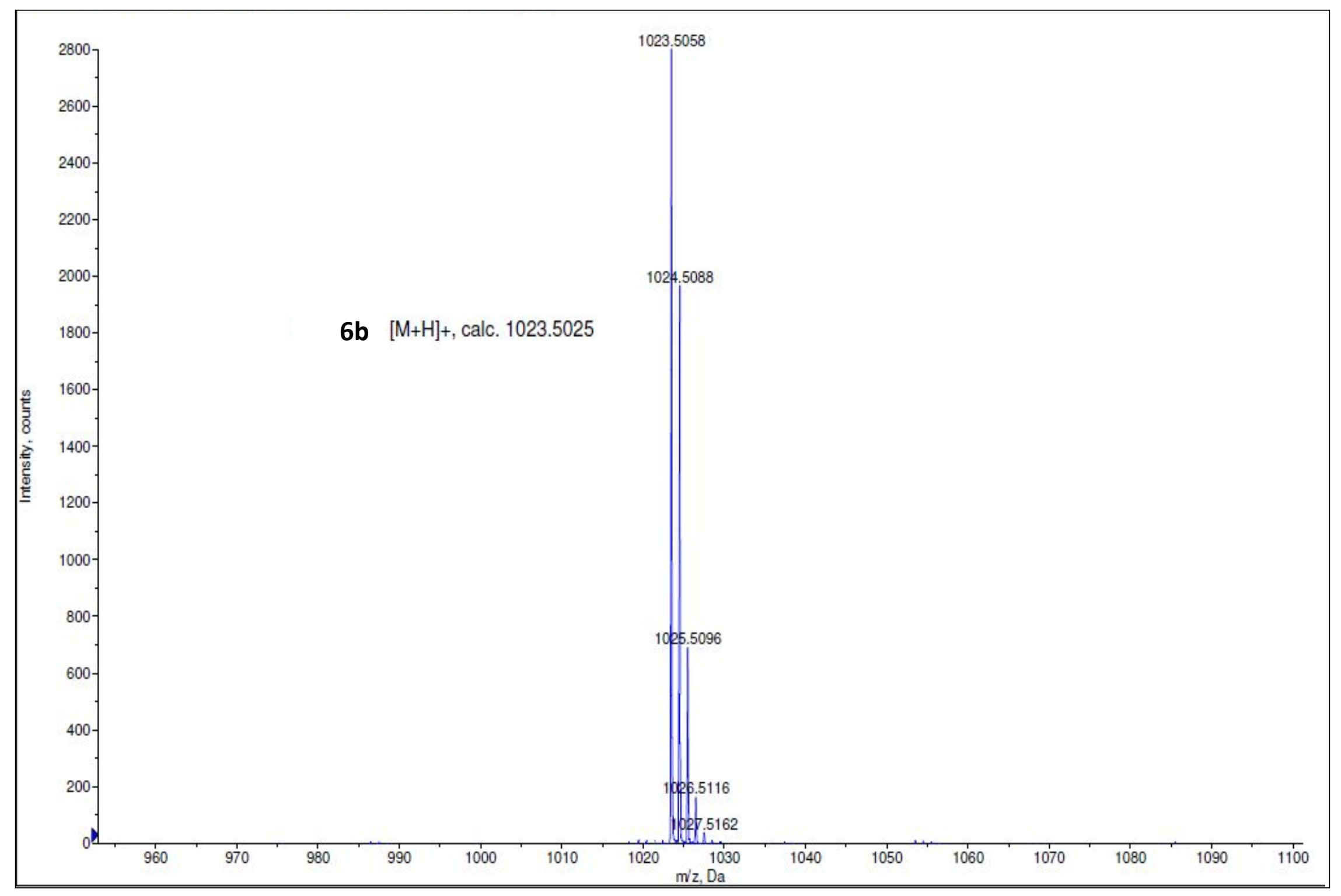

Figure S11. MS spectrum of 8N-(6-aminochrysene)-3',5'-O-bis(tert-butyldimethylsilyl)-N'-dimethoxytrityl-2'-deoxyadenosine (6b) 


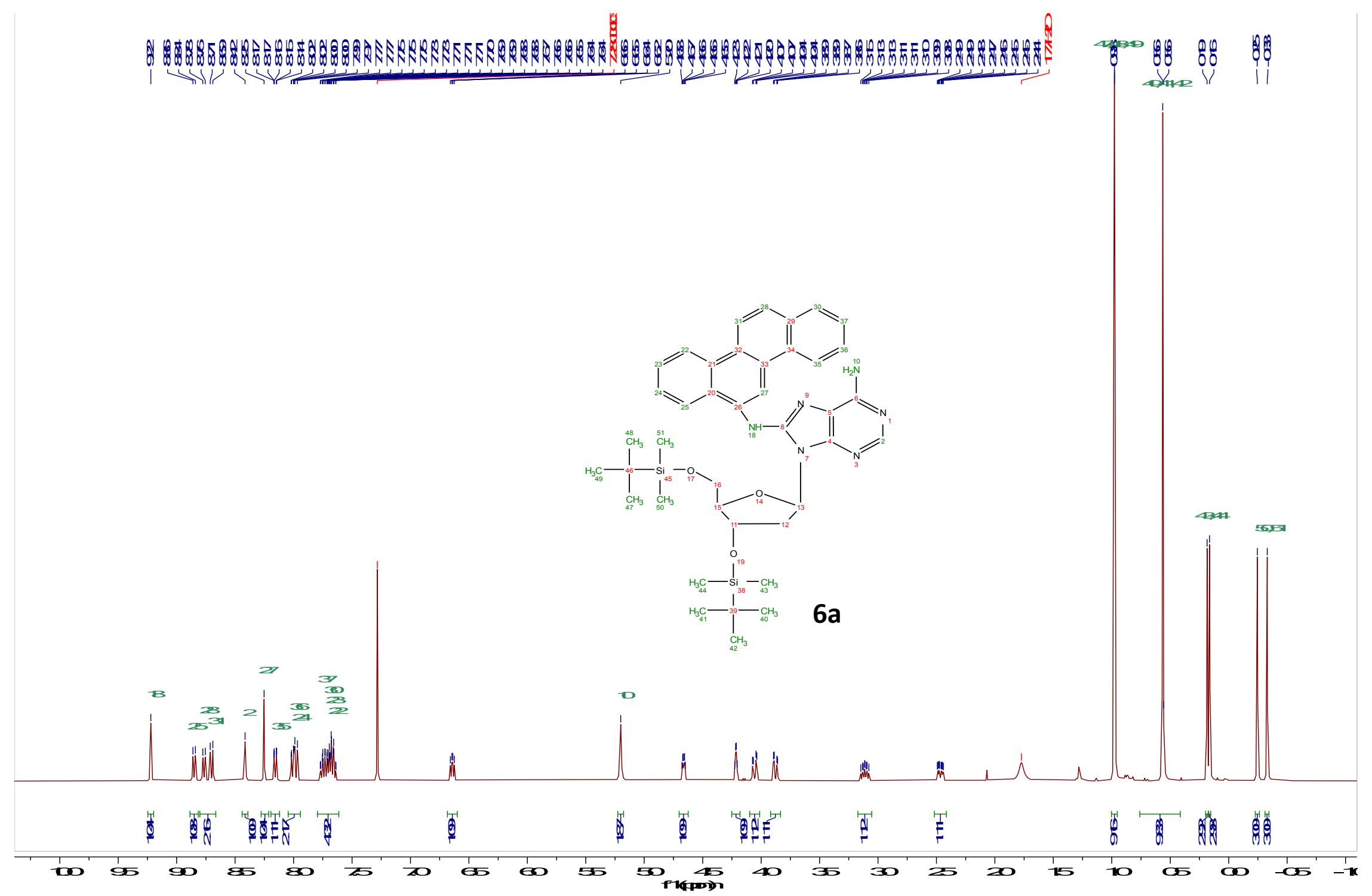

Figure S12. ${ }^{1} \mathrm{H}$ NMR spectrum of 8N-(6-aminochrysene)-3',5'-O-bis(tert-butyldimethylsilyl)-2'-deoxyadenosine (6a) 


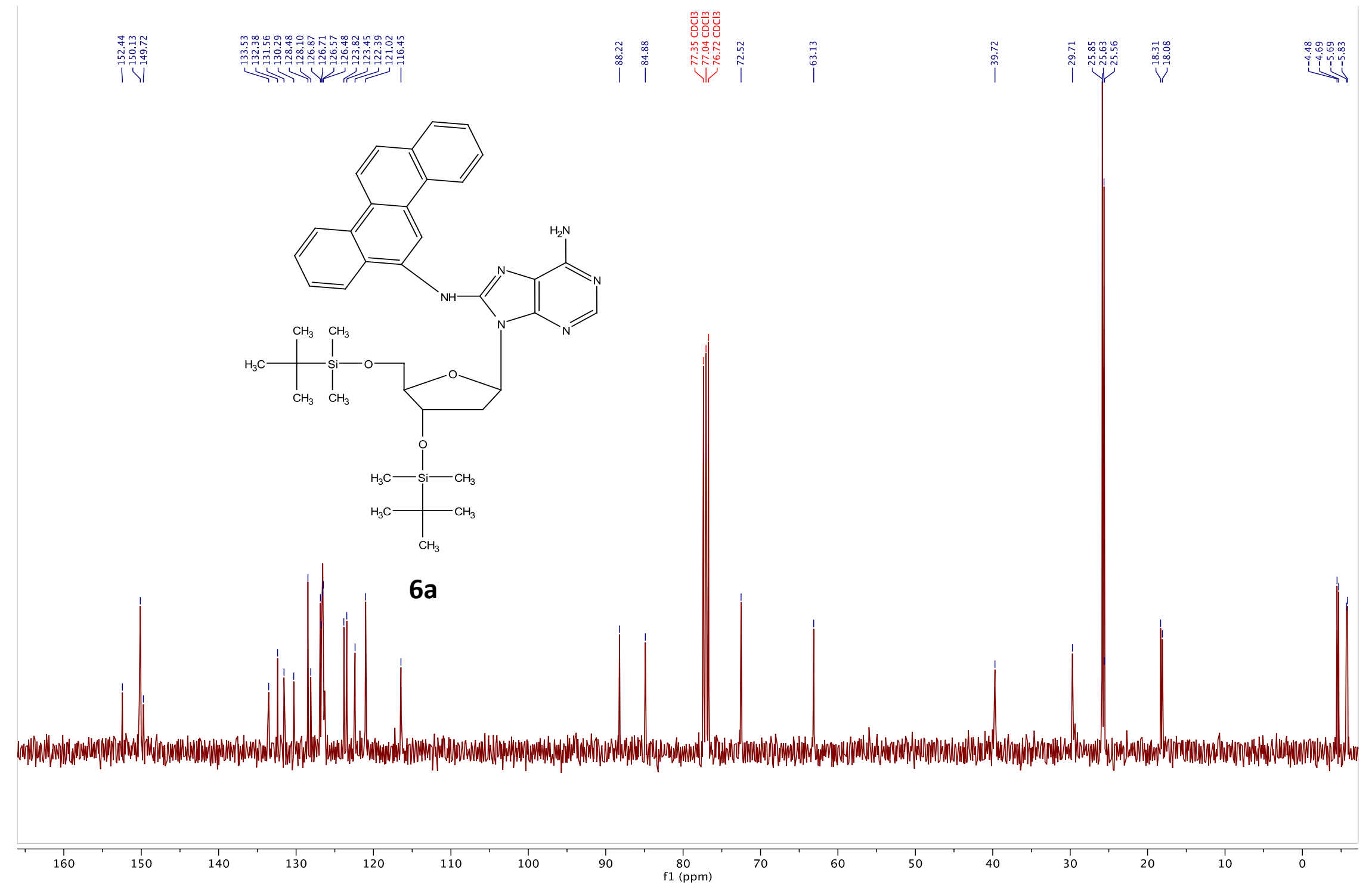

Figure S13. ${ }^{13} \mathrm{C}$ NMR spectrum of $8 \mathrm{~N}-(6$-aminochrysene)-3',5'-O-bis(tert-butyldimethylsilyl)-2' -deoxyadenosine (6a) 


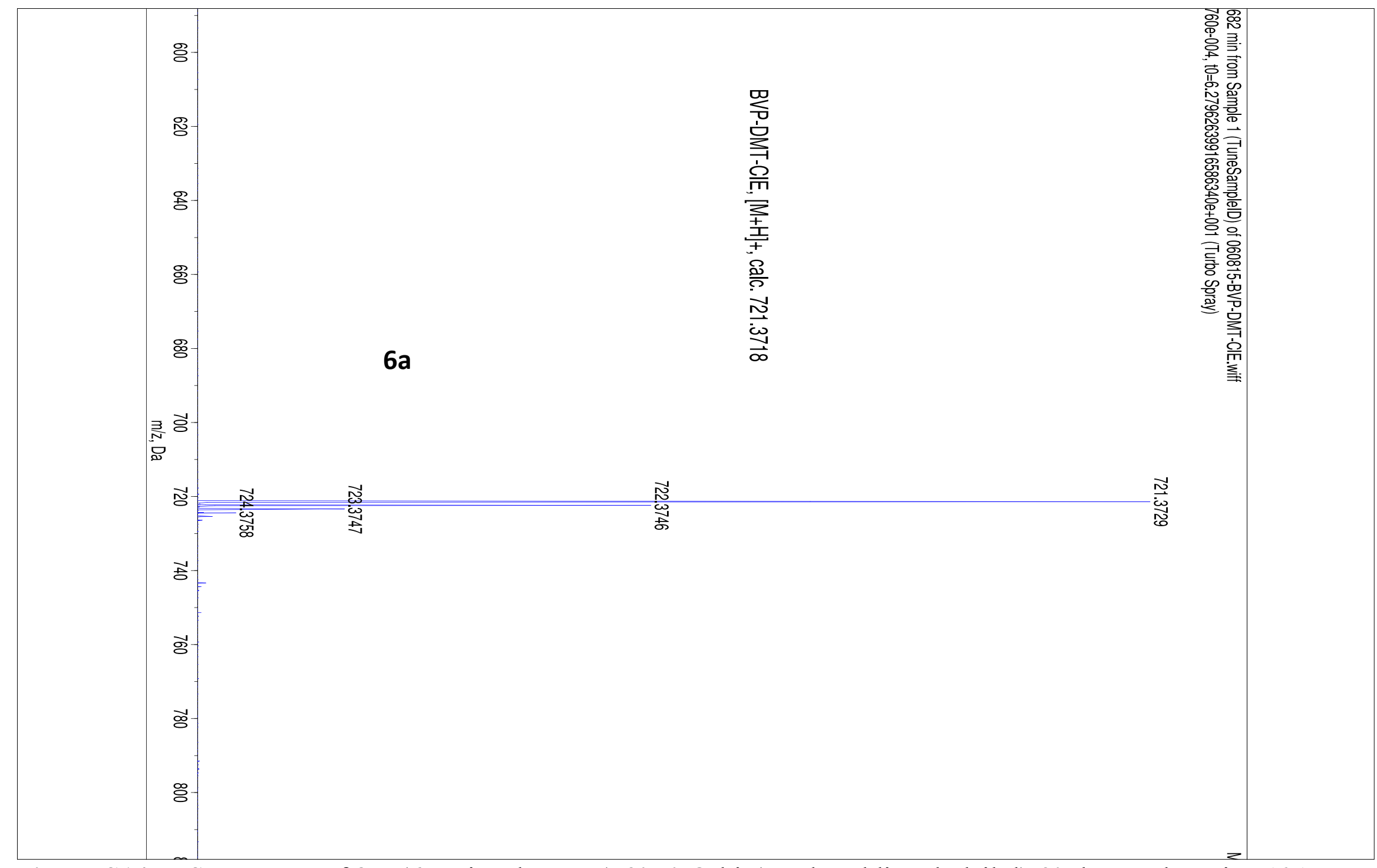

Figure S14. MS spectrum of 8N-(6-aminochrysene)-3',5'-O-bis(tert-butyldimethylsilyl)-2'-deoxyadenosine (6a) 

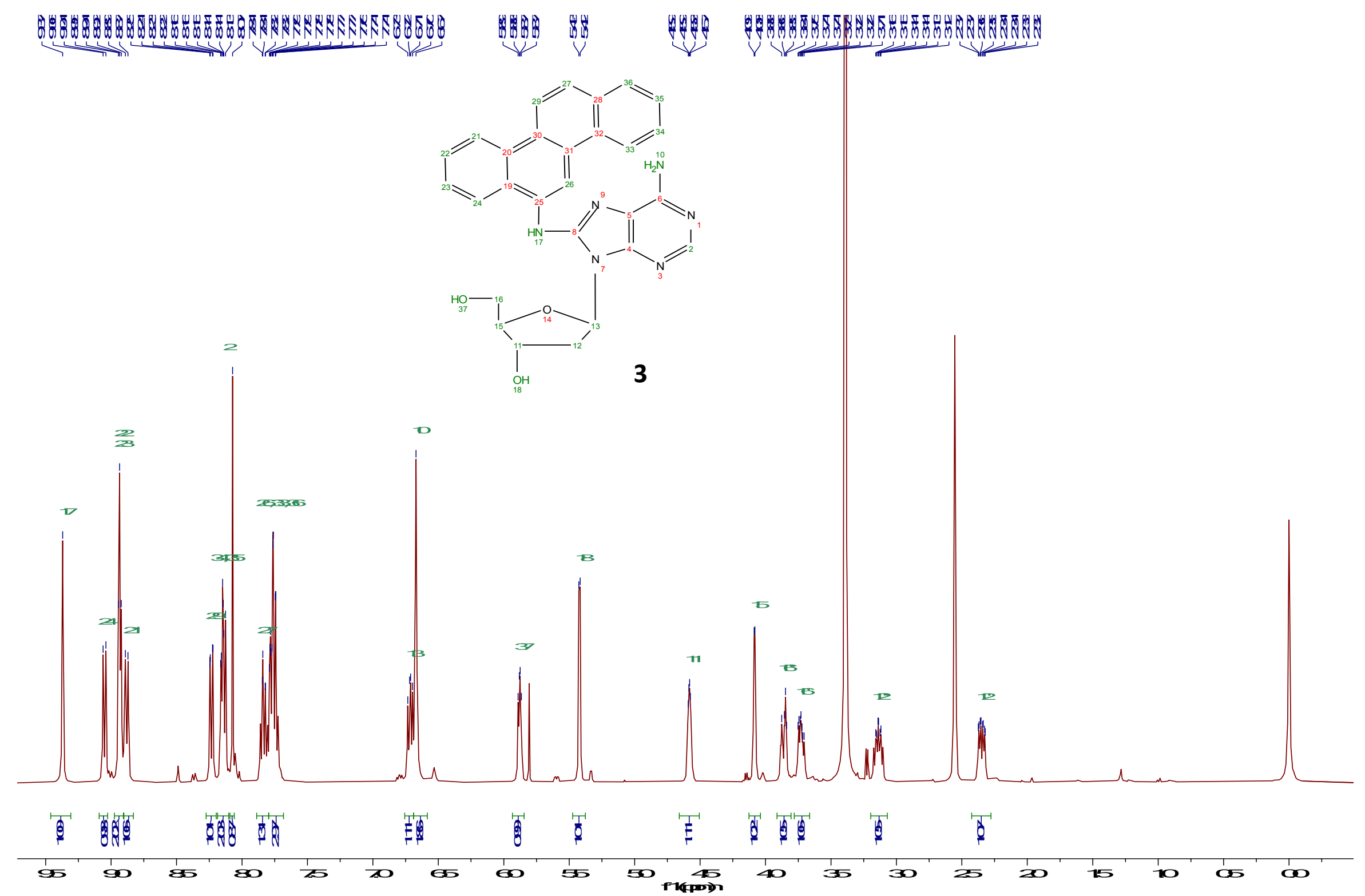

Figure S15. ${ }^{1} \mathrm{H}$ NMR spectrum of 8N-(6-aminochrysene)-2'-deoxyadenosine (3) 

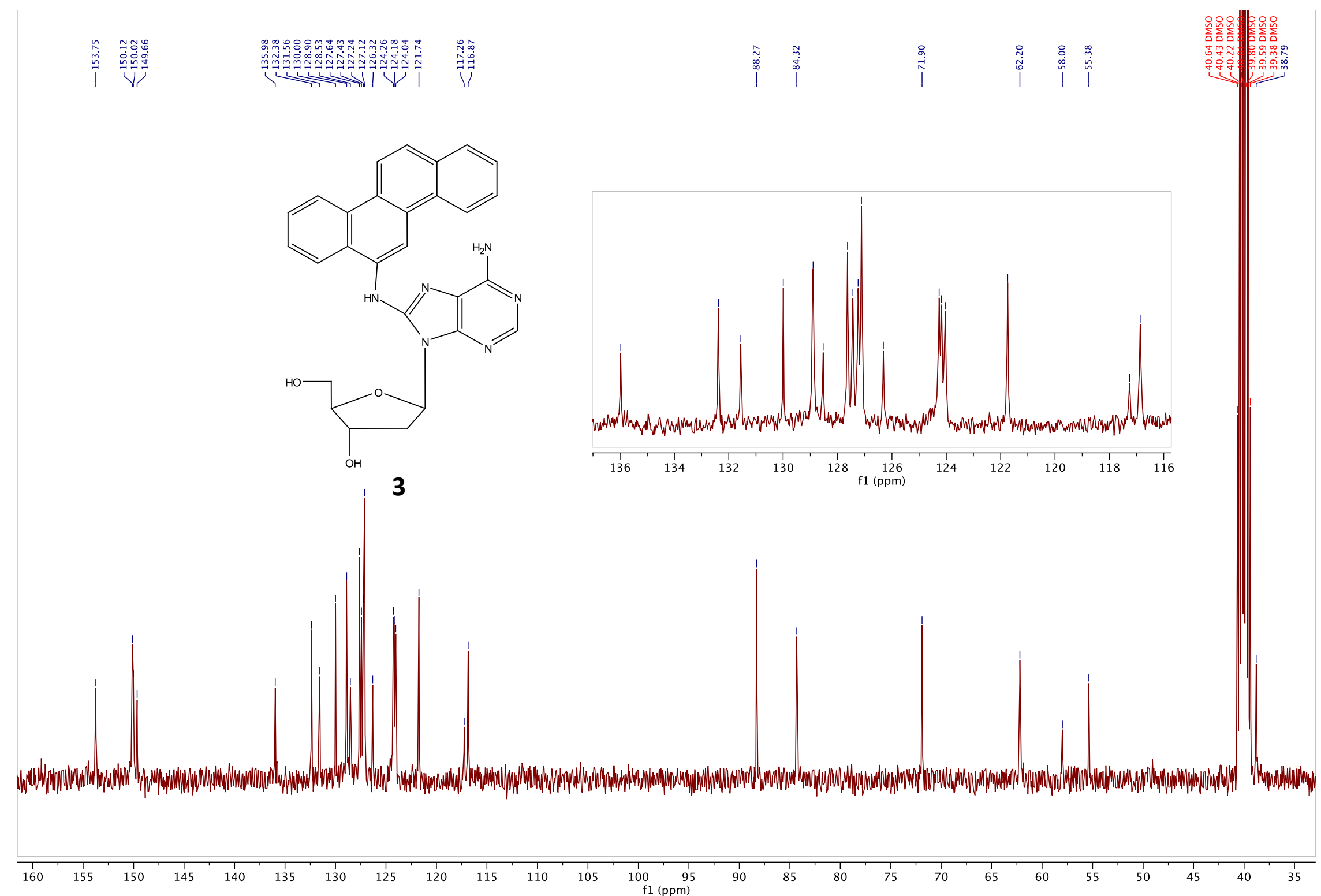

Figure S16. ${ }^{13} \mathrm{C}$ NMR spectrum of 8N-(6-aminochrysene)-2'-deoxyadenosine (3) 


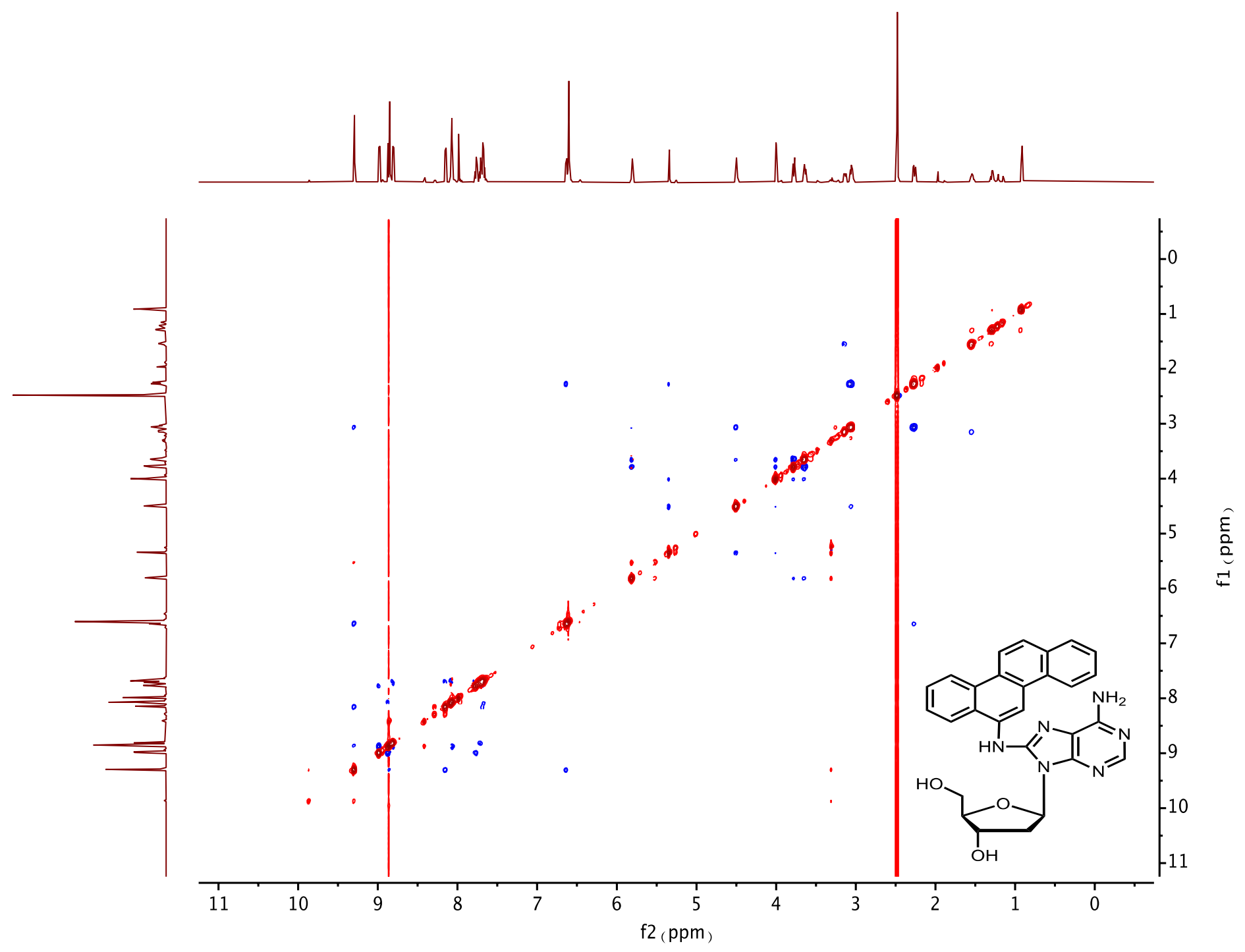

Figure S17. ${ }^{1} \mathrm{H}-{ }^{1} \mathrm{H}$ ROESY NMR spectrum of 8N-(6-aminochrysene)-2'-deoxyadenosine (3) 
+Q1: 1.474 min from Sample 1 (TuneSamplelD) of MT20180911141757.wiff (Turbo Spray)

Max. $9.5 \mathrm{e} 5 \mathrm{cps}$
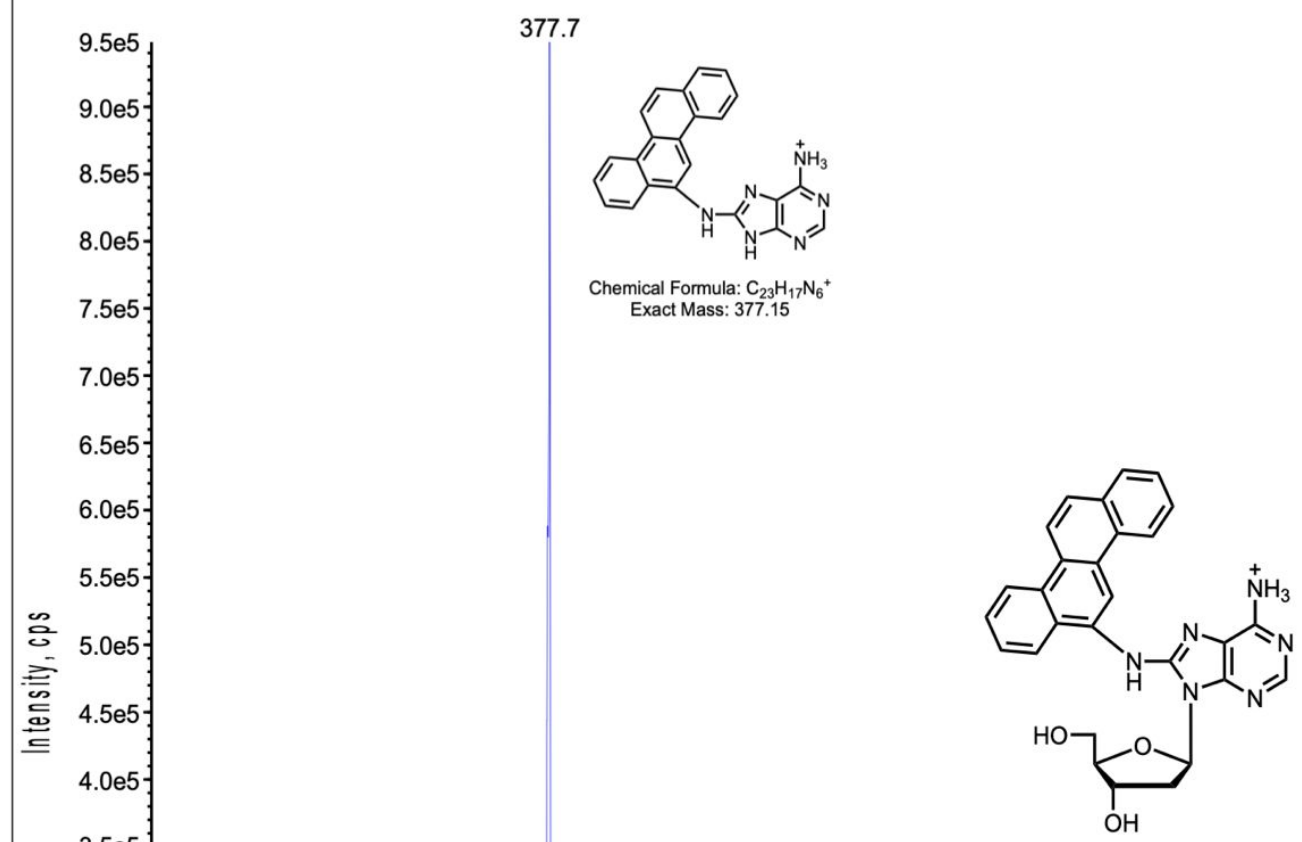

3

493.3
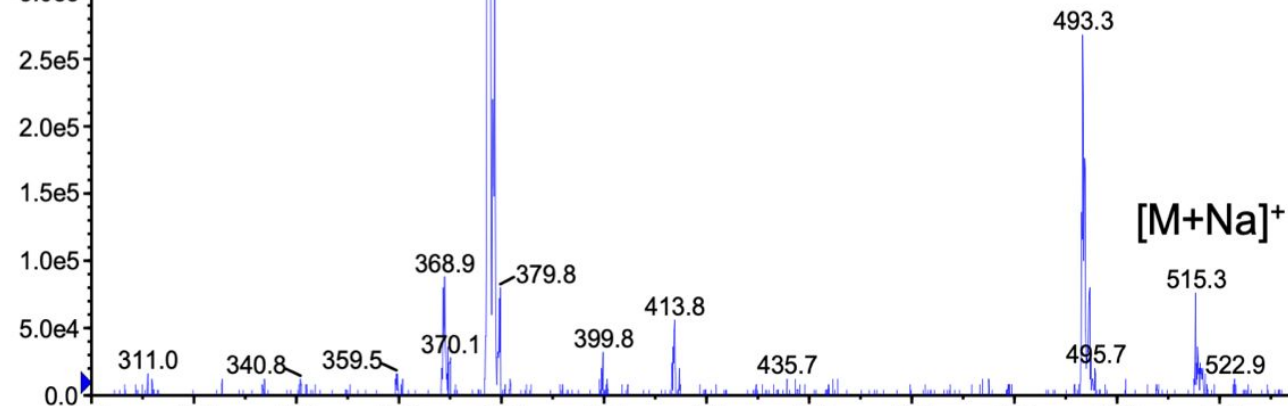

515.3

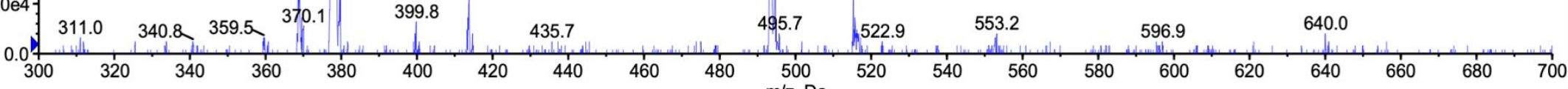

Figure S18. MS spectrum of 8N-(6-aminochrysene)-2'-deoxyadenosine (3) 


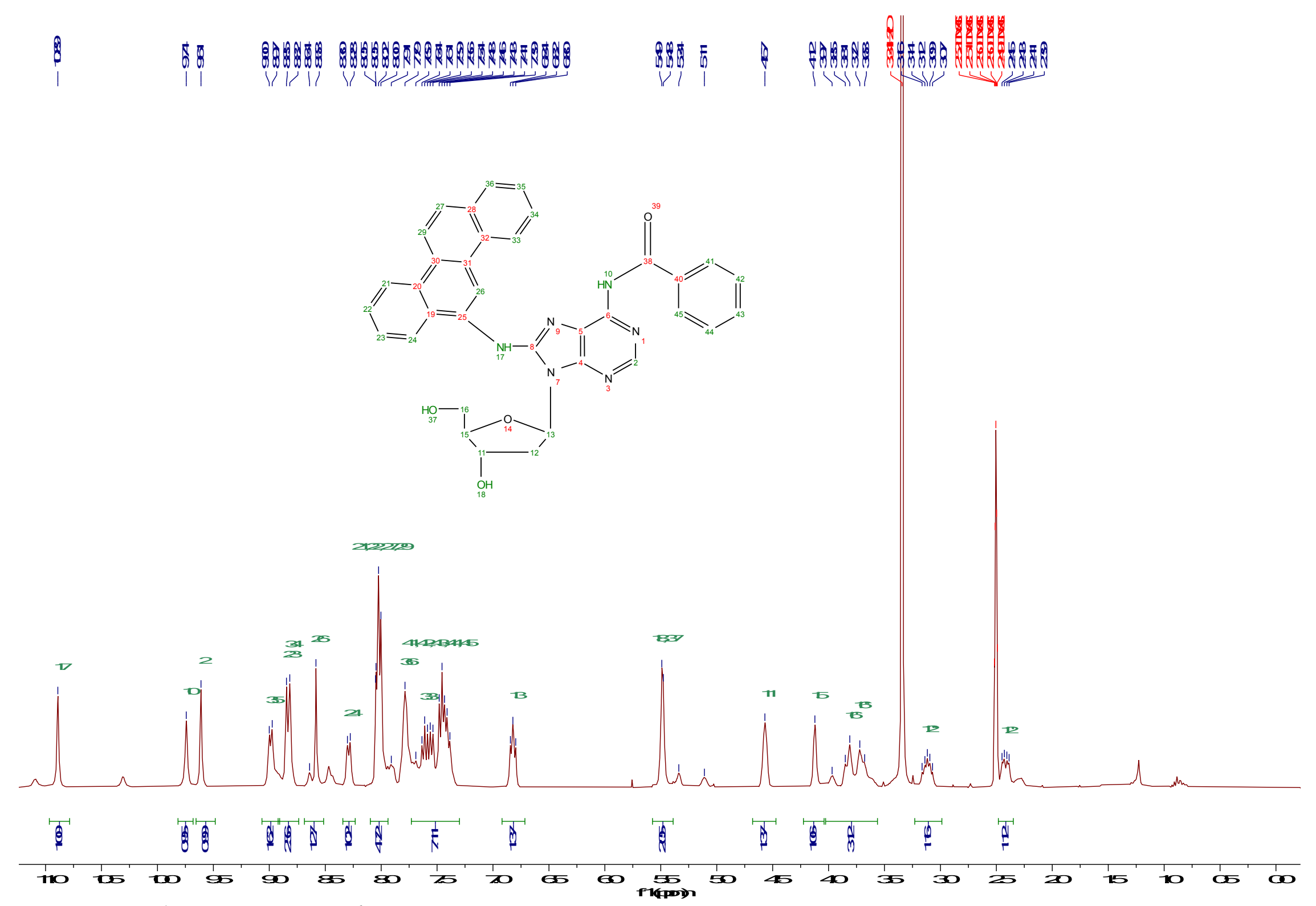

Figure S19. ${ }^{1} \mathrm{H}$ spectrum of $N^{6}$-Benzoyl-8N-(aminochrysene)-2'-deoxyadenosine (7) 

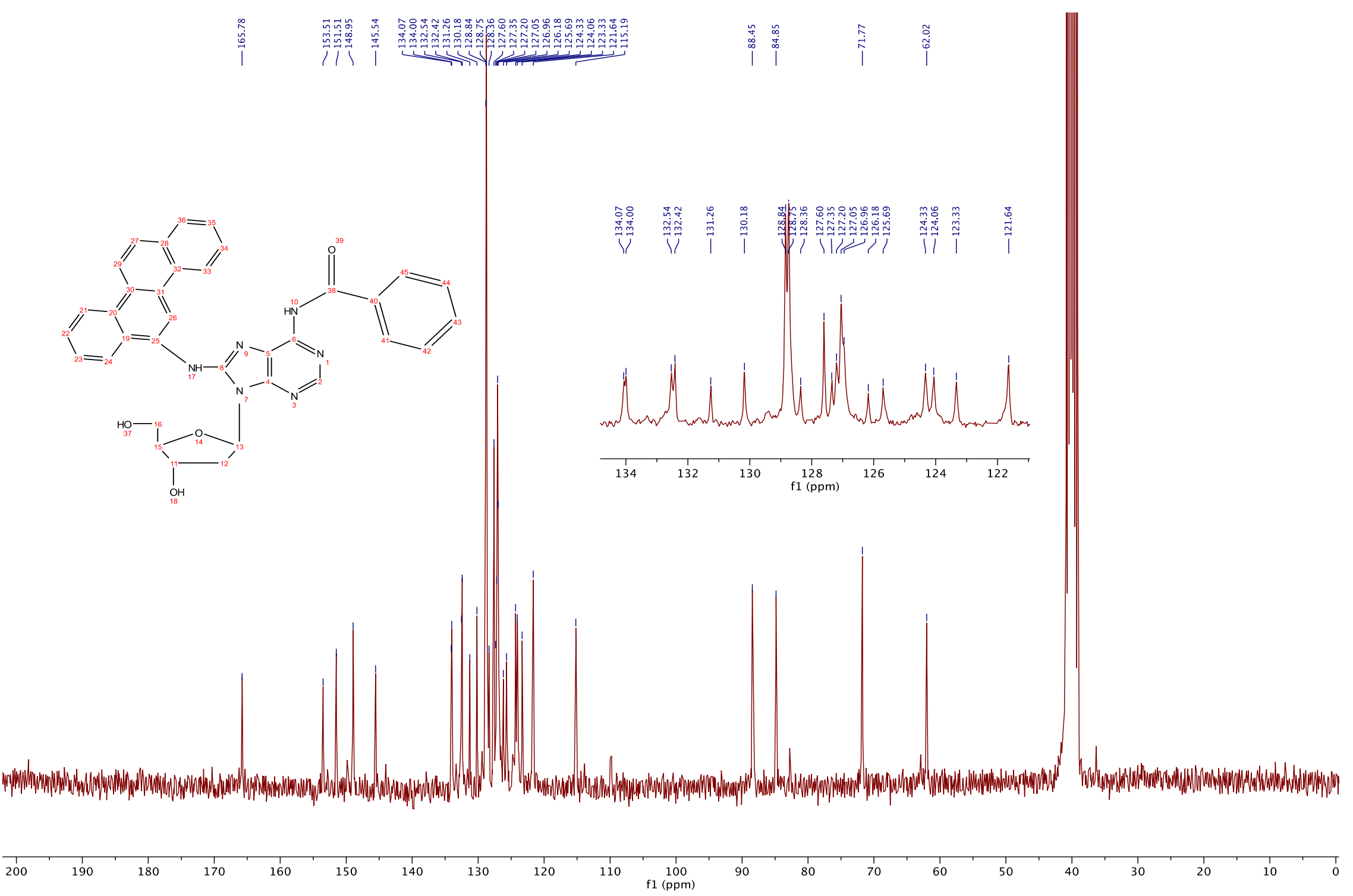

Figure S20. ${ }^{13} \mathrm{C}$ spectrum of $N^{6}$-Benzoyl- $8 N$-(aminochrysene)-2'-deoxyadenosine (7) 


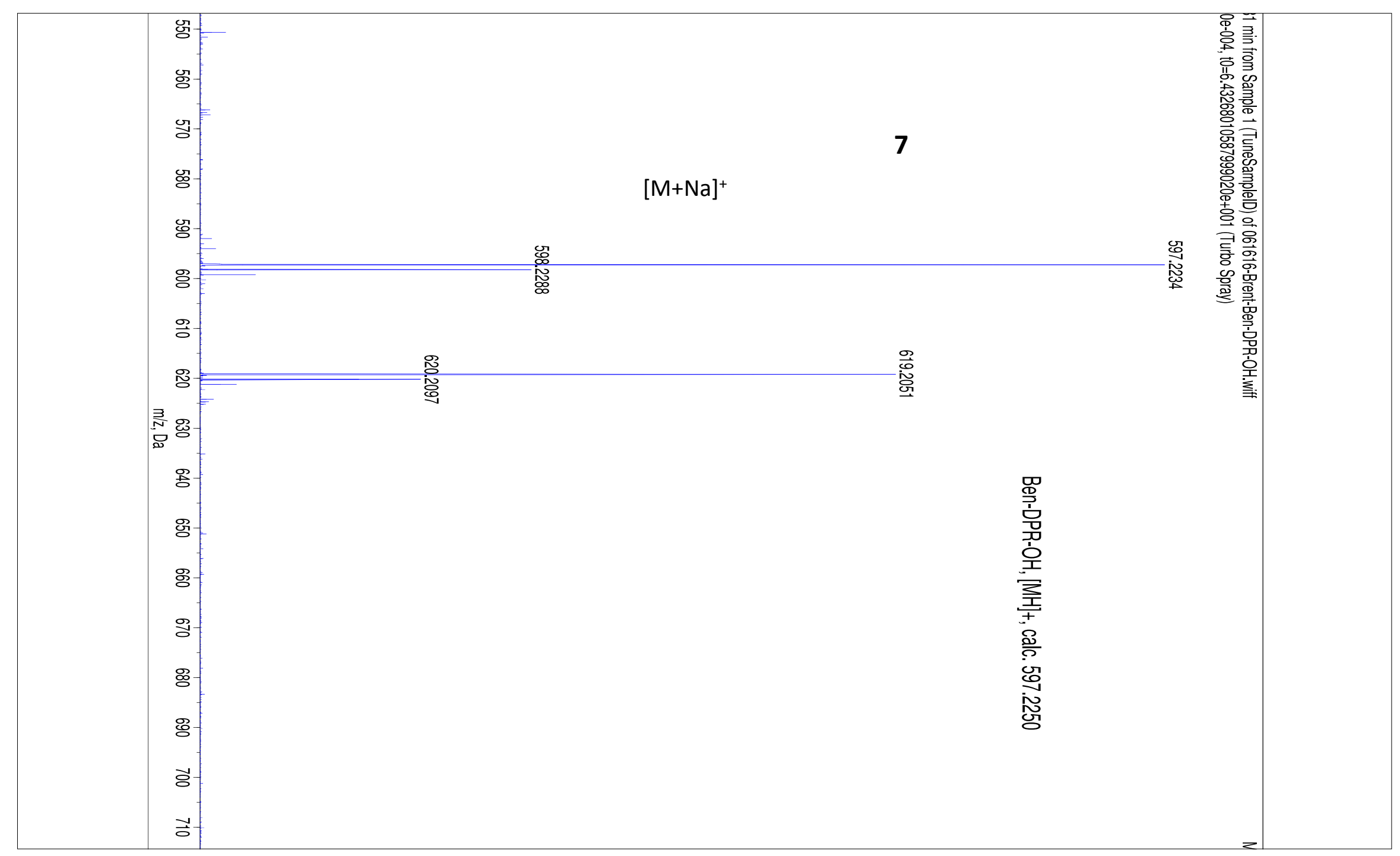

Figure S21. MS spectrum of $N^{6}$-Benzoyl-8N-(aminochrysene)-2'-deoxyadenosine (7) 


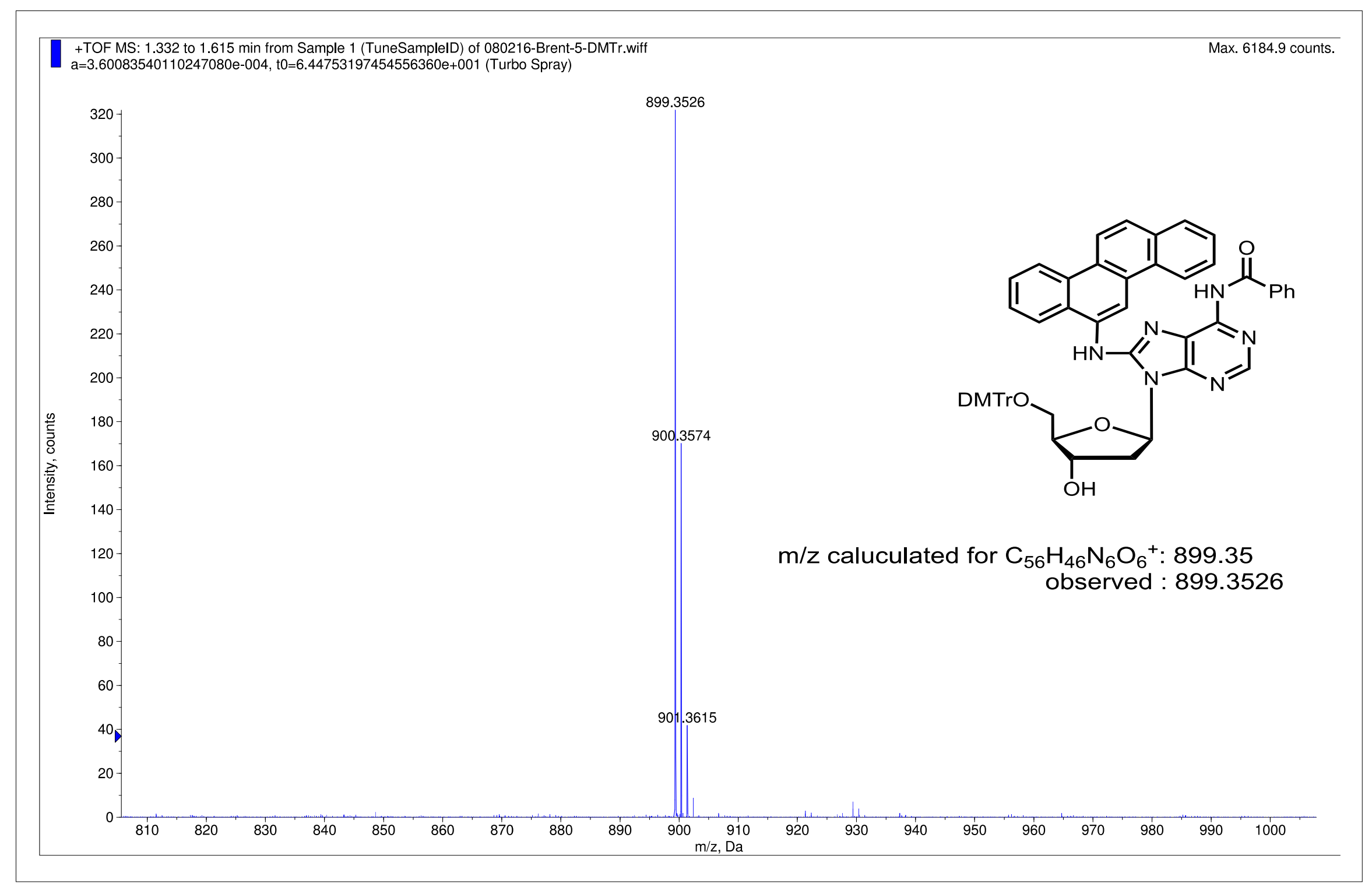

Figure S22. MS spectrum of $N^{6}$-Benzoyl- $8 N$-(6-aminochrysene)-5'-O-dimethoxytrityl-2'-deoxyadenosine 


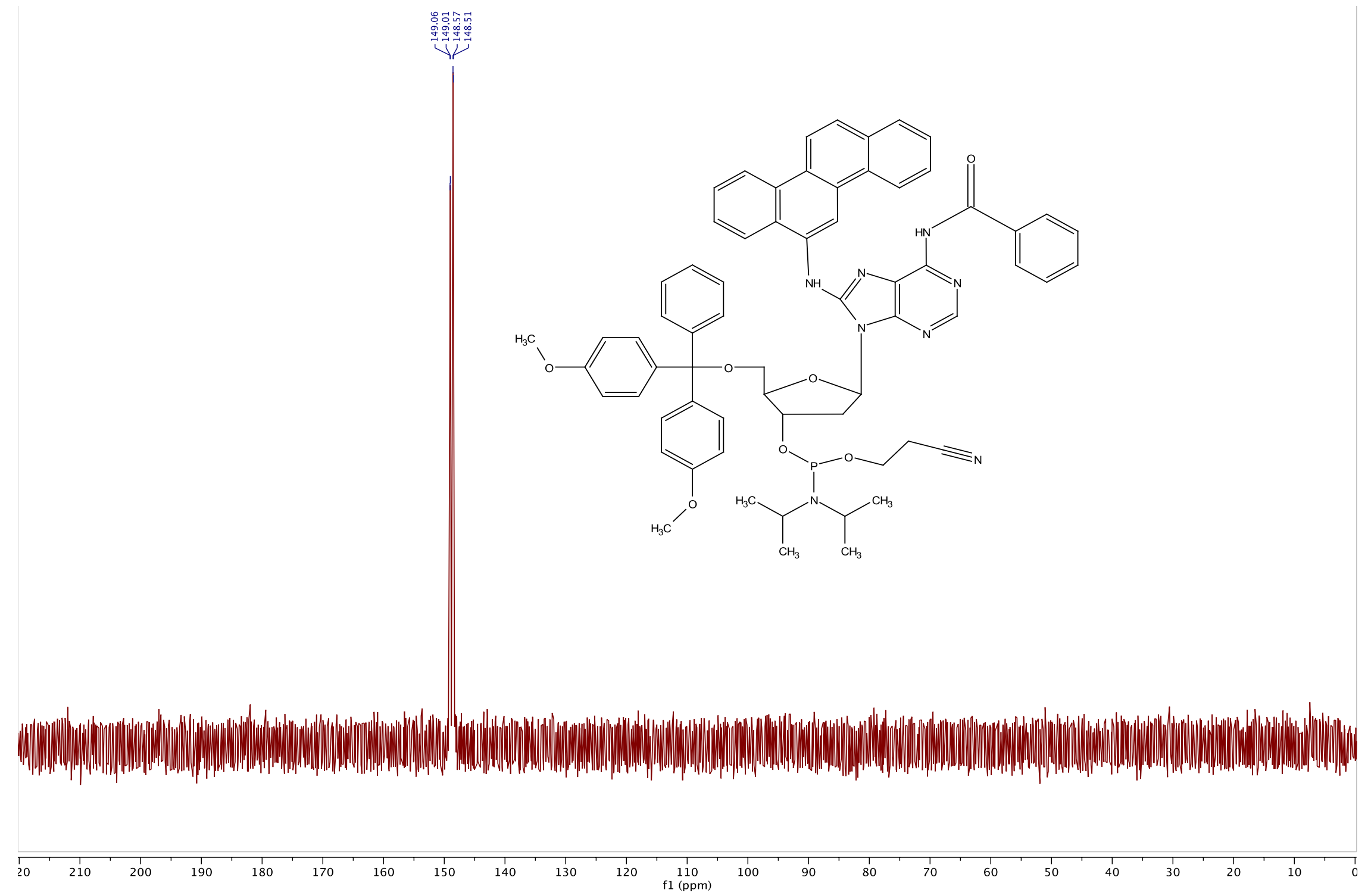

Figure S23. ${ }^{31} \mathrm{P}$ spectrum of $N^{6}$-Benzoyl-8N-(6-aminochrysene)-5'-O-dimethoxytrityl-2'-deoxyadenosine-3'-O(cyanoethyl-N,N'-diisopropyl-phosphoramidite (8) 


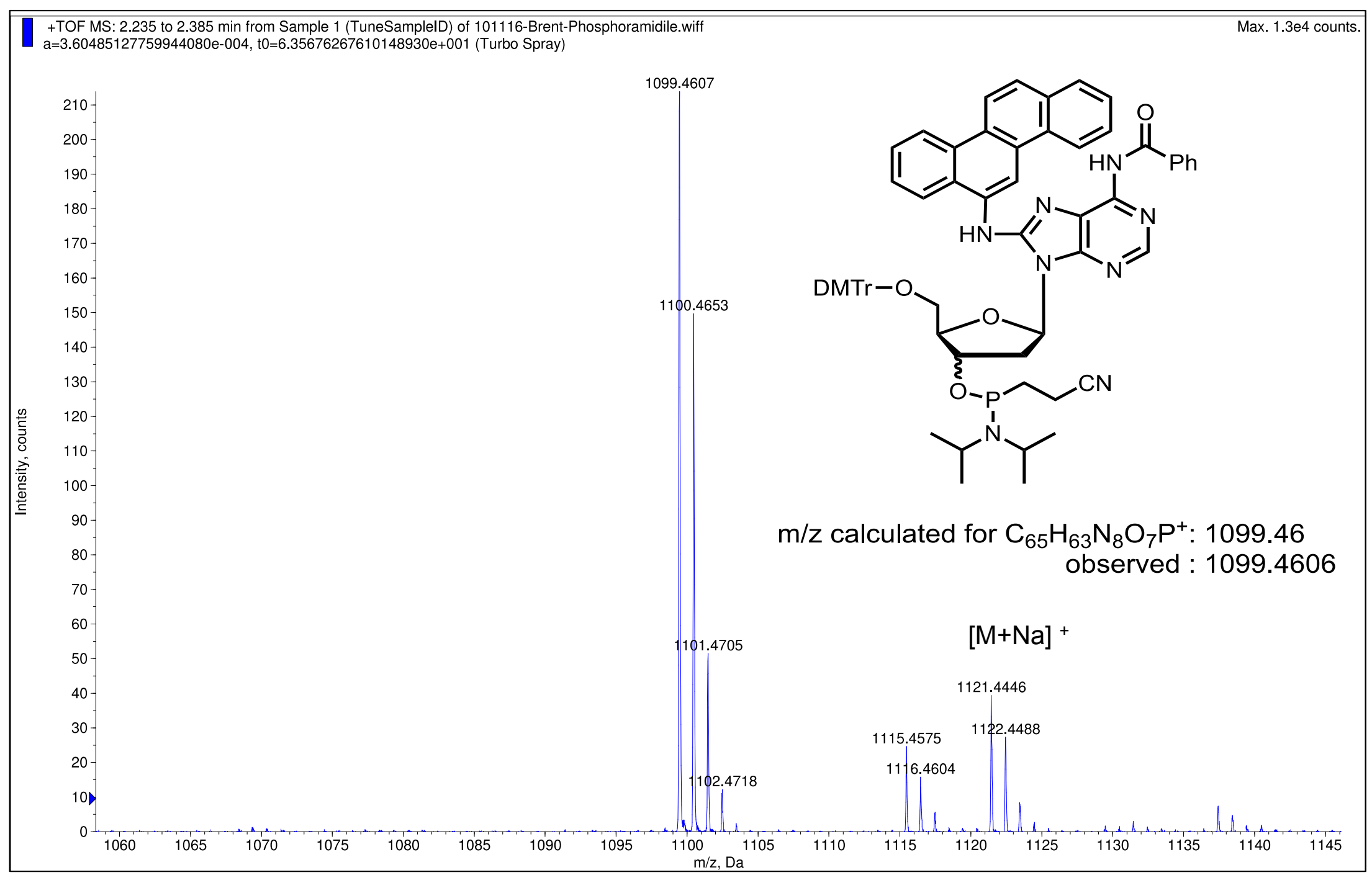

Figure S24. MS spectrum of $N^{6}$-Benzoyl-8N-(6-aminochrysene)-5'-O-dimethoxytrityl-2'-deoxyadenosine-3'-O(cyanoethyl-N,N'-diisopropyl-phosphoramidite (8) 


\section{5'-GTGCA*TGTTTGT-3'}

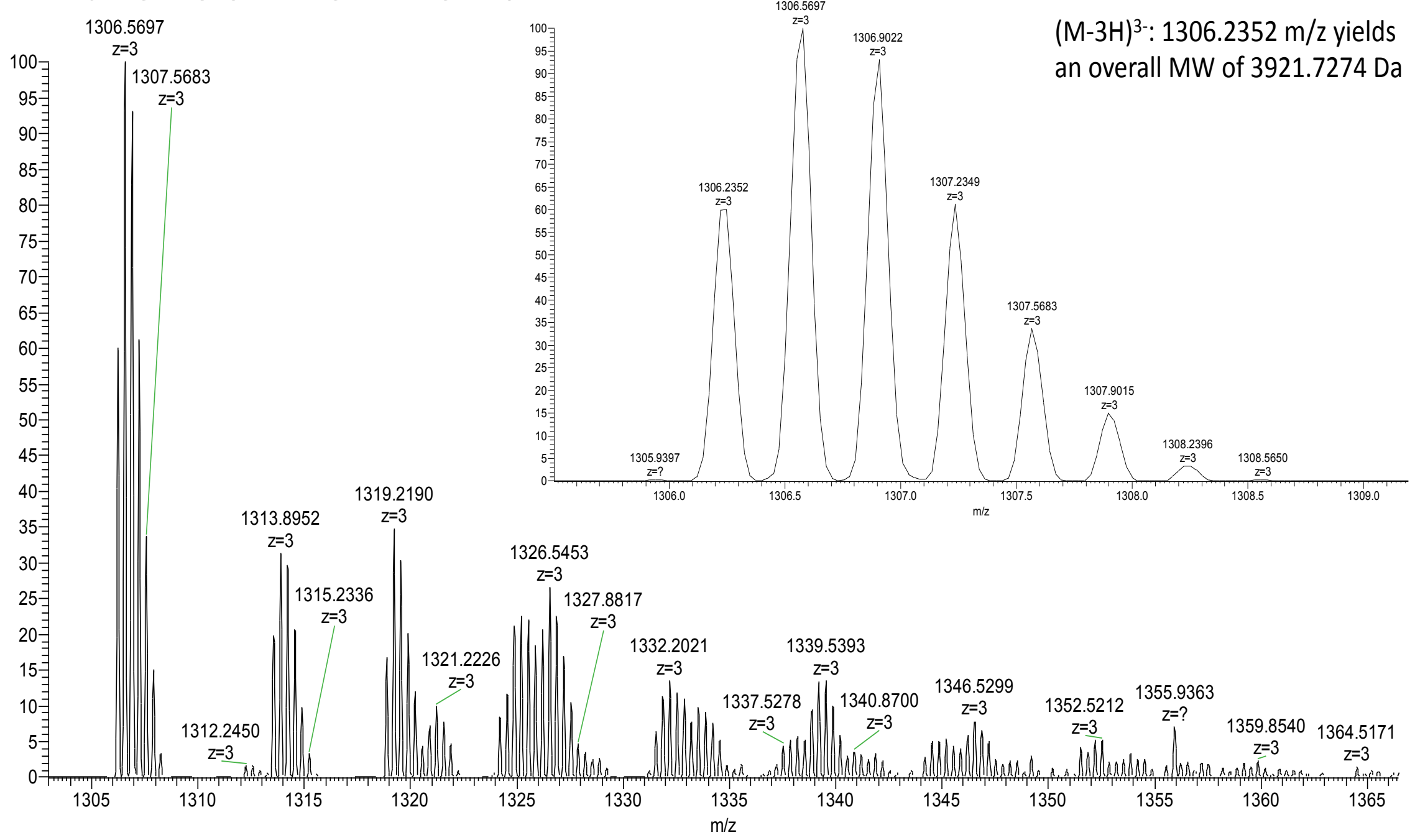

Figure S25. ESI-MS (negative mode) spectrum of $N$-(dA-8-yl)-6-AC modified 12-mer oligodeoxynucleotide 
5'-GCCCTCAA*CAAGATG-3'

1195.7207

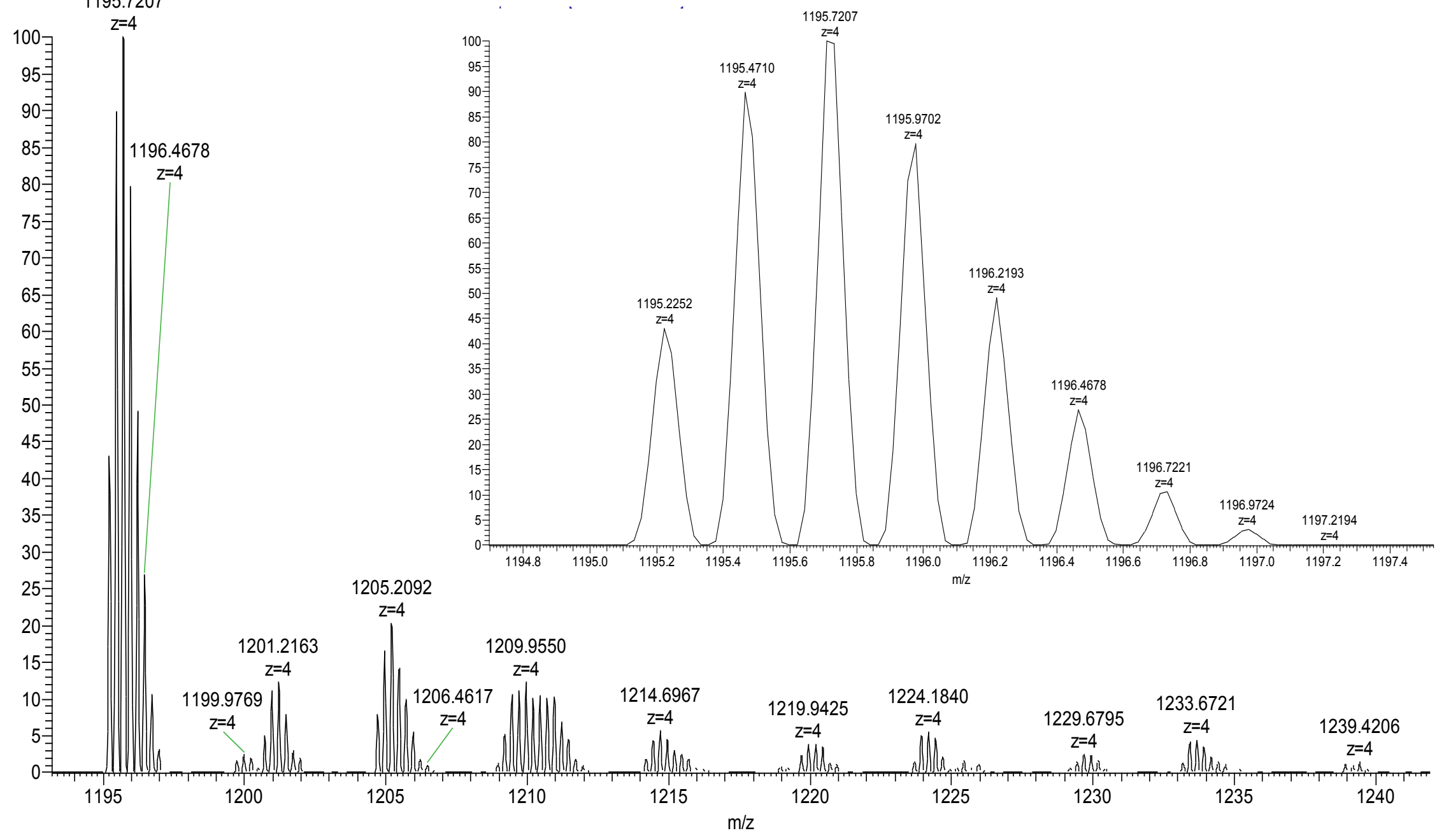

Figure S26. ESI-MS (negative mode) spectrum of $N$-(dA-8-yl)-6-AC modified 15-mer oligodeoxynucleotide 


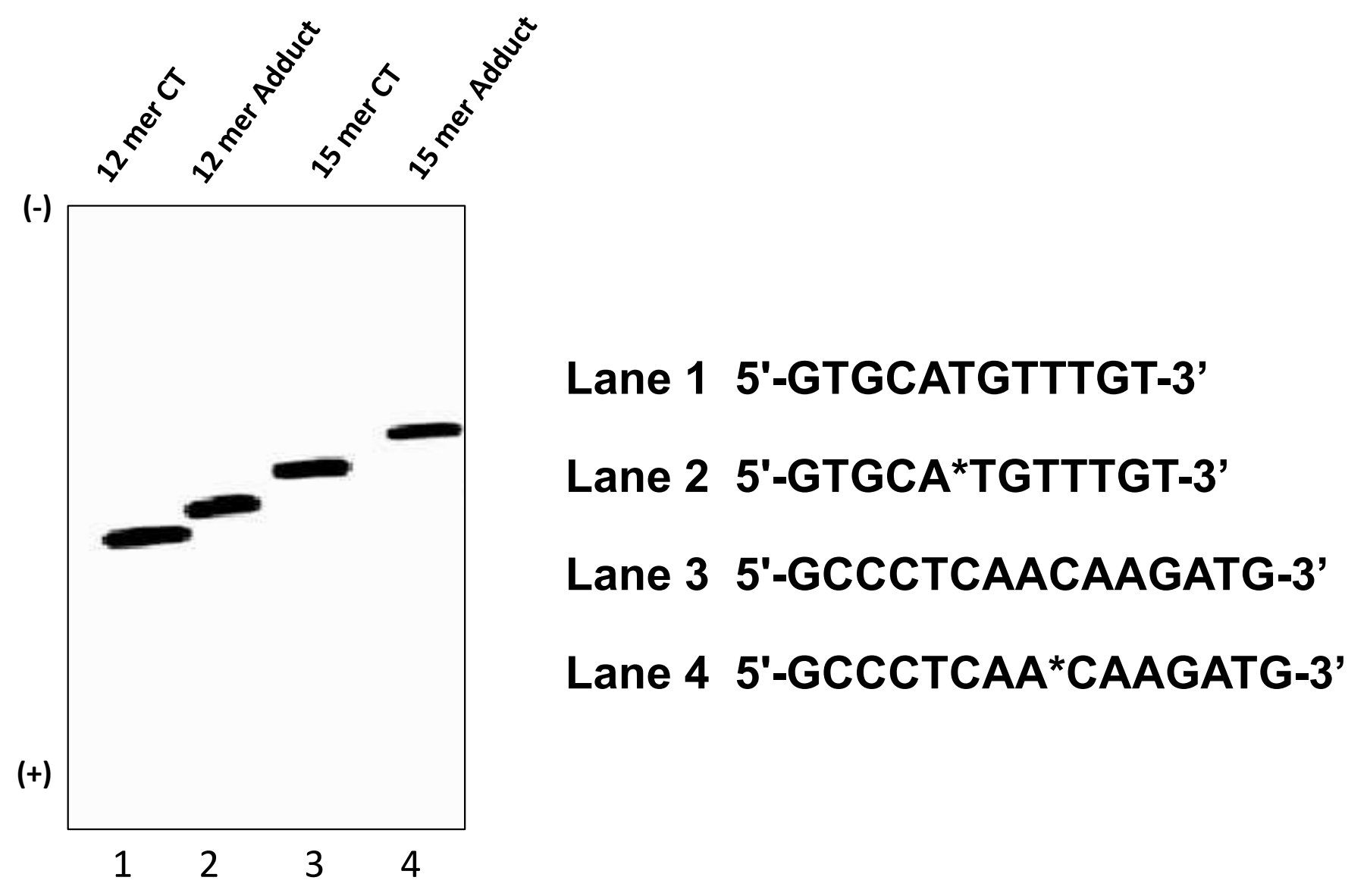




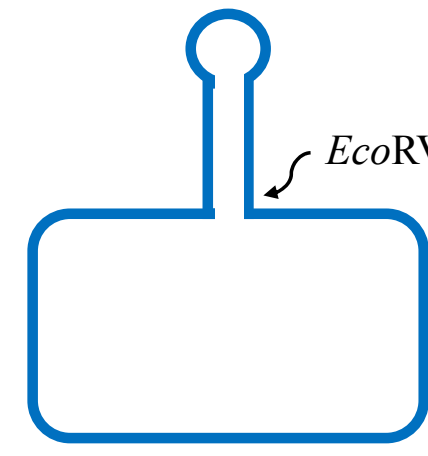

pMS2 plasmid

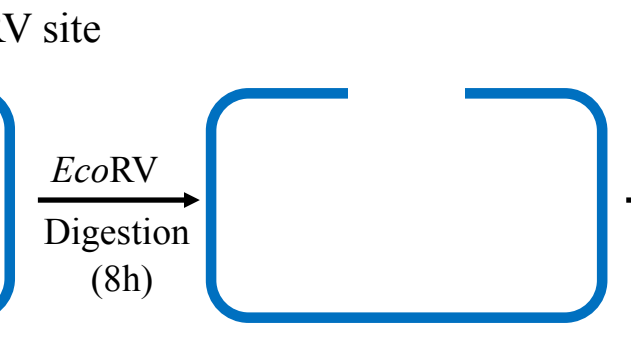

linear plasmid

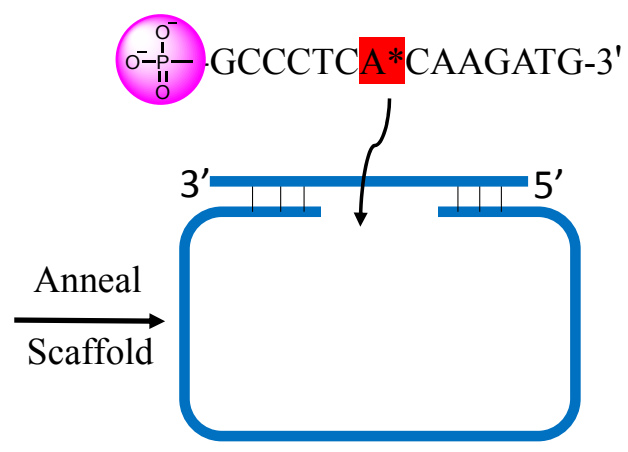

gapped duplex

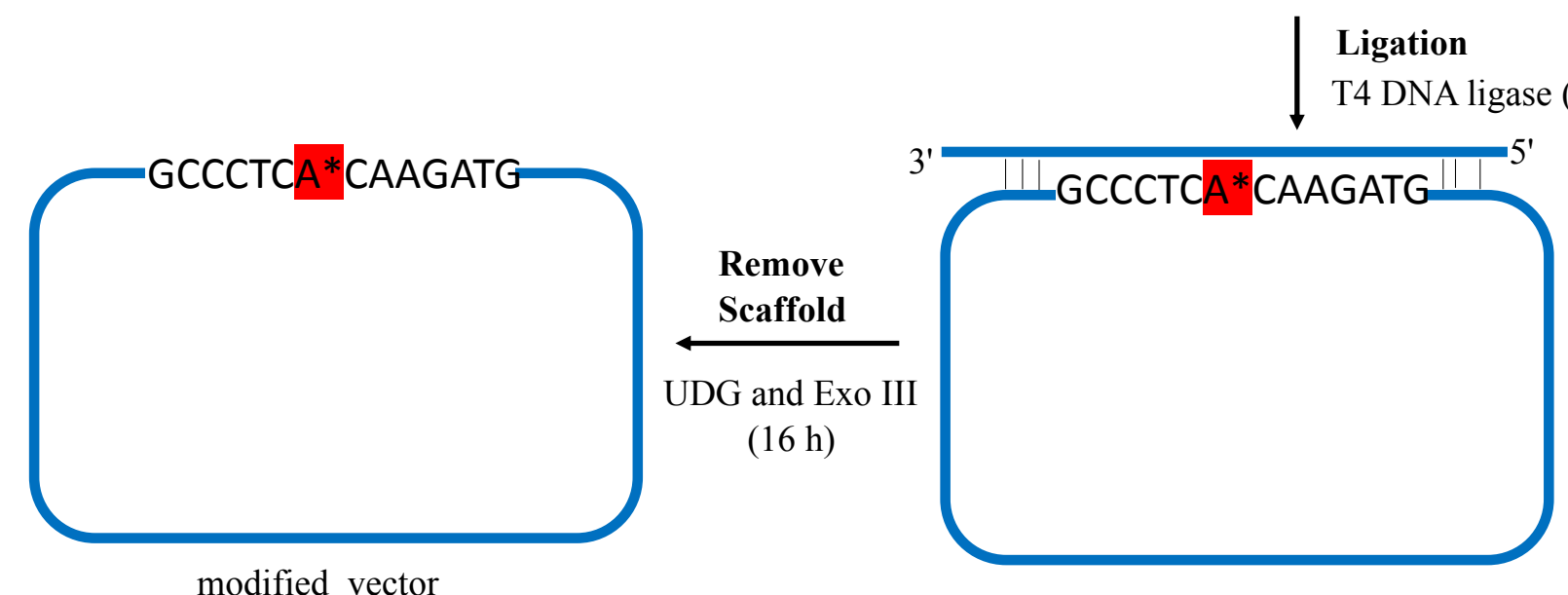

modified vector

Scheme S1. Summary of the procedure for construction of recombinant DNA vector. The scaffold was removed by enzymatic digestion with uracil DNA glycosylase (UDG, 05 units/ $\mu \mathrm{l})$ and exonuclease-III $(0.5$ units/ $\mu \mathrm{L})$ at $16{ }^{\circ} \mathrm{C}$ overnight. 


\section{$5^{\prime}-G_{1} C_{1} C_{2} C_{3} T_{1} C_{4} A_{1} A^{*}{ }_{2} C_{3} A_{3} A_{4} G_{2} A T G_{3}-3^{\prime}$}

\begin{tabular}{|c|c|c|c|c|c|c|c|c|c|}
\hline \multicolumn{10}{|c|}{ Replication in E. coli Strain AB1157 } \\
\hline \multirow[t]{2}{*}{ Exp \# } & \multirow{2}{*}{$\begin{array}{l}\text { Total } \\
\text { colonies } \\
\text { screened }\end{array}$} & \multirow{2}{*}{$\begin{array}{l}\text { Total } \\
\text { no. of } \\
\text { mutants }\end{array}$} & \multirow[t]{2}{*}{ MF (\%) } & \multirow[t]{2}{*}{$\begin{array}{c}\% \\
\text { Survival }\end{array}$} & \multicolumn{4}{|c|}{ Targeted Mutations } & \multirow{2}{*}{$\begin{array}{l}\text { Semi-Targeted Mutations } \\
\text { [no. of mutants] (\%) }\end{array}$} \\
\hline & & & & & $\begin{array}{l}\mathrm{A}^{* \rightarrow \mathrm{T}} \\
(\%)\end{array}$ & $\begin{array}{l}A^{* \rightarrow G} \\
(\%)\end{array}$ & $\begin{array}{l}\mathrm{A}^{* \rightarrow C} \mathrm{C} \\
(\%)\end{array}$ & $\begin{array}{l}\mathrm{A}^{* \mathrm{del}} \\
(\%)\end{array}$ & \\
\hline $1(-) \mathrm{SOS}$ & 149 & 9 & 6.0 & $65^{* *}$ & $\begin{array}{l}0 \\
--\end{array}$ & $\begin{array}{c}4 \\
(2.68)\end{array}$ & $\begin{array}{l}0 \\
--\end{array}$ & $\begin{array}{c}0 \\
--\end{array}$ & $\begin{array}{l}5^{\prime}-\mathrm{A}_{1} \mathrm{~A}^{*}{ }_{2} \mathrm{C} \rightarrow \mathrm{TGC}[4](2.7) \\
5^{\prime}-\mathrm{G}_{1} \mathrm{C}_{1} \mathrm{C}_{2} \rightarrow \mathrm{GGC}[1](0.7) \\
5^{\prime}-\mathrm{A}_{3} \mathrm{~A}_{4} \mathrm{G}_{2} \rightarrow{ }_{-} \mathrm{AG}[4](2.7)\end{array}$ \\
\hline $2(-) \mathrm{SOS}$ & 98 & 3 & $\overline{3.0}$ & $62^{*}$ & $\begin{array}{l}0 \\
--\end{array}$ & $\begin{array}{c}2 \\
(2.04)\end{array}$ & $\begin{array}{l}0 \\
--\end{array}$ & $\begin{array}{l}0 \\
--\end{array}$ & $\begin{array}{l}5^{\prime}-\mathrm{A}_{1} \mathrm{~A}_{2}{ }_{2} \mathrm{C} \rightarrow \mathrm{TGC}[2](2.0) \\
\mathrm{A}_{3} \mathrm{~A}_{4} \mathrm{G}_{2} \rightarrow{ }_{-} \mathrm{AG}[1](1.0)\end{array}$ \\
\hline $3(-)$ SOS & 265 & 15 & $\overline{5.6}$ & $58 * * *$ & $\begin{array}{c}2 \\
(0.75)\end{array}$ & $\begin{array}{c}6 \\
(2.26)\end{array}$ & $\begin{array}{l}0 \\
--\end{array}$ & $\begin{array}{l}0 \\
--\end{array}$ & $\begin{array}{l}\mathrm{A}_{1} \mathrm{~A}^{*}{ }_{2} \mathrm{C} \rightarrow \mathrm{TGC}[2](0.8) \\
5^{\prime}-\mathrm{G}_{1} \mathrm{C}_{1} \mathrm{C}_{2} \rightarrow \text { GGC [1] (0.3) } \\
\mathrm{A}^{*}{ }_{2} \mathrm{C}_{3} \mathrm{~A}_{3} \mathrm{~A}_{4} \mathrm{G}_{2} \mathrm{ATG} \text { del. [3] (1.1) } \\
5^{\prime}-\mathrm{C}_{4} \mathrm{~A}_{1} \mathrm{~A}^{*}{ }_{2} \text { deletion [1] (0.8) } \\
\mathrm{C}_{3} \text { del [1] }(0.3) \\
5{ }^{\prime}-\mathrm{A}_{2}{ }_{2} \mathrm{C}_{3} \mathrm{~A}_{3} \mathrm{~A}_{4} \mathrm{G}_{2} \mathrm{ATG} \text { [1] (0.3) }\end{array}$ \\
\hline $4(-)$ SOS & $\overline{158}$ & 8 & $\overline{5.0}$ & $51^{*}$ & $\begin{array}{c}1 \\
(0.6)\end{array}$ & $\begin{array}{c}4 \\
(2.53)\end{array}$ & $\begin{array}{l}0 \\
--\end{array}$ & $\begin{array}{c}1 \\
(0.6)\end{array}$ & $\begin{array}{l}\mathrm{A}_{1} \mathrm{~A}^{*}{ }_{2} \mathrm{C} \rightarrow \mathrm{TGC}[1](0.6) \\
\mathrm{A}_{1} \text { or } \mathrm{A}^{*}{ }_{2} \operatorname{del}[1](0.6)\end{array}$ \\
\hline $\begin{array}{l}\text { (-) SOS } \\
\text { TOTALS }\end{array}$ & 670 & 35 & $5.2 \%$ & 59 & $\begin{array}{c}3 \\
(0.45 \%)\end{array}$ & $\begin{array}{c}16 \\
(2.4 \%)\end{array}$ & $\begin{array}{l}0 \\
--\end{array}$ & 1 & $\begin{array}{c}16 \\
(2.4 \%)\end{array}$ \\
\hline
\end{tabular}




\begin{tabular}{|c|c|c|c|c|c|c|c|c|c|}
\hline $\begin{array}{c}1 \\
(+) \mathrm{SOS}\end{array}$ & 183 & 25 & 13.6 & $89 * * *$ & $\begin{array}{c}3 \\
(1.64)\end{array}$ & $\begin{array}{c}9 \\
(4.92)\end{array}$ & $\begin{array}{c}7 \\
(3.82)\end{array}$ & $\begin{array}{c}0 \\
--\end{array}$ & $\begin{array}{l}\mathrm{G}_{1} \rightarrow \mathrm{C}[1](0.54) \\
\mathrm{G}_{3} \rightarrow \mathrm{A}[1](0.54) \\
\mathrm{G}_{3} \text { del [1] }(0.54) \\
\mathrm{C}_{3} \mathrm{~T}_{1} \mathrm{C}_{4} \rightarrow \mathrm{TT}_{1} \mathrm{~A}[1](0.54) \\
5^{\prime}-\mathrm{C}_{3} \mathrm{~T}_{1} \mathrm{C}_{4} \mathrm{~A}_{1} \text { del [2] (1.09) }\end{array}$ \\
\hline $\begin{array}{c}\mathbf{2} \\
(+) \mathrm{SOS}\end{array}$ & 127 & 13 & 10.23 & $85 * * *$ & $\begin{array}{c}2 \\
(1.57)\end{array}$ & $\begin{array}{c}7 \\
(5.51)\end{array}$ & $\begin{array}{c}1 \\
(0.78)\end{array}$ & $\begin{array}{c}0 \\
--\end{array}$ & $\begin{array}{l}5^{\prime}-\mathrm{C}_{3} \mathrm{~A}_{3} \mathrm{~A}_{4} \text { del [1] }(0.79) \\
\mathrm{T}_{1} \operatorname{del}[1](0.79) \\
\mathrm{C}_{1} \rightarrow \mathrm{A}[1](0.79)\end{array}$ \\
\hline $\begin{array}{l}\text { (+) SOS } \\
\text { TOTALS }\end{array}$ & 310 & 38 & $12.2 \%$ & 87 & $\begin{array}{c}5 \\
(1.61)\end{array}$ & $\begin{array}{c}16 \\
(5.16)\end{array}$ & $\begin{array}{c}8 \\
(2.58)\end{array}$ & $\begin{array}{l}\mathbf{0} \\
--\end{array}$ & $\begin{array}{c}10 \\
(3.2 \%)\end{array}$ \\
\hline
\end{tabular}

*3 Plates Average; **3-6 Plates Average; ***6-12 Plates Average

Table S1. Mutational frequency in wild type (-) SOS and (+) SOS E. coli (AB1157) cells 